NBER WORKING PAPER SERIES

\title{
DOES CHILD LABOR DECLINE WITH IMPROVING ECONOMIC STATUS?
}

\author{
Eric V. Edmonds \\ Working Paper 10134 \\ http://www.nber.org/papers/w10134 \\ NATIONAL BUREAU OF ECONOMIC RESEARCH
1050 Massachusetts Avenue
Cambridge, MA 02138
December 2003
}

I am grateful to Amitabh Chandra, Andrew Foster, Paul Glewwe, Nina Pavcnik, Bruce Sacerdote, Doug Staiger, Carrie Turk, and seminar participants at NEUDC and Dartmouth College for comments and helpful suggestions. Correspondence to Eric Edmonds, Department of Economics, Dartmouth College, 6106 Rockefeller Hall, Hanover, NH 03755 USA, eedmonds@dartmouth.edu. First draft entitled "Will Child Labor Decline with Improvements in Living Standards," July 2001. http://www.dartmouth.edu/ eedmonds/ The views expressed herein are those of the authors and not necessarily those of the National Bureau of Economic Research.

(C)2003 by Eric V. Edmonds. All rights reserved. Short sections of text, not to exceed two paragraphs, may be quoted without explicit permission provided that full credit, including $(\subset$ notice, is given to the source. 
Does Child Labor Decline with Improving Economic Status?

Eric V. Edmonds

NBER Working Paper No. 10134

December 2003

JEL No. J82, J22, O15

\section{ABSTRACT}

From 1993 to 1997, GDP per capita in Vietnam grew by between 6 and 7 percent annually. Child labor declined by 28 percent over this period. Using a simple, nonparametric decomposition, I investigate the relationship between improvements in per capita expenditure and child labor with a panel dataset of Vietnamese households that spans this episode of growth. I find that improvements in per capita expenditure can explain 80 percent of the decline in child labor that occurs in households whose expenditures improve enough to move out of poverty. This finding suggests a previously undocumented role for economic growth in the amelioration of child labor.

Eric V. Edmonds

Department of Economics

Dartmouth College

6106 Rockefeller Hall

Hanover, NH 03755

and NBER

eedmonds@dartmouth.edu 


\section{Introduction}

Few issues in the lives of the world's poor receive more attention from rich country observers than child labor. There are two distinct literatures on the relationship between improvements in economic status (generally measured by income or total expenditure) and changes in child labor (typically defined as the employment of children in wage work or in the family farm or enterprise). One line of research considers whether child labor may be a cause of poverty and may help perpetuate the intergenerational transmission of depravation through its impact on human capital accumulation. ${ }^{1}$ The present study contributes to a second strand of research that considers the role low family income plays in the decision to have a child work. The cross-country picture suggests a strong link between child labor and GDP per capita (Krueger 1997) as does the economic history of many developed economies (Moehling 1999 for example). These images have contributed to a common view among many economists, implicit in many contemporary theoretical pieces on child labor supply, that child labor would be reduced significantly by rising incomes. ${ }^{2}$

However, this view that child labor will decline with rising economic status has recently encountered significant academic opposition. Several studies have used cross-sectional household survey data to argue against a strong link between economic status and child labor by comparing the activities of children in different households that vary in their income (see Brown,

\footnotetext{
${ }^{1}$ Working children may bring income into the household and thereby ameliorate poverty. Children may also learn skills while working that bring a return later in life (Beegle, Dehejia, and Gatti 2003b). On the other hand, the presence of children in the labor market may depress wages for adults and thereby create poverty (Basu and Van 1998). Moreover, child labor may conflict with school attendance (e.g. Boozer and Suri 2001), it may reduce the time children invest in study and thereby school performance and attainment (e.g. Heady 2003), it may impair child development through diminished play and leisure, and child labor may be associated with worse health and nutritional status because of the environment in which children work (e.g. Fassa 2003). Through these mechanisms, child labor may create an intergenerational poverty trap. For formal presentations see Basu (1999), Emerson and Souza (2002), and Hazan and Berdugo (2002).

${ }^{2}$ This result follows from studies where child labor is a bad in parental preferences such as Basu and Van (1998), Baland and Robinson (2000), Ranjan (2001), and Bommier and Dubios (2003). Rogers and Swinnerton (2003) point out that rising incomes can increase child labor if credit market imperfections induce parents to over-invest in education as a way of securing income for parents in the future (via transfers from children).
} 
Deardorff and Stern 2003 or Basu and Tzannatos 2004 for recent surveys). ${ }^{3}$ The absence of a strong negative correlation between economic status and child labor within a cross-section in a country is often interpreted in two ways. First, if child labor is not a bad in parental preferences because of cultural norms or parental attitudes, then improvements in income may have no effect on the economic activities of children (e.g. Ennew 1992 , Ray 2000, or Deb and Rosati 2002). In fact, researchers as far back as Marx have argued that variation in child labor is primarily labor demand driven (Basu 1999). Second, to the extent that improvements in economic status come from increases in market earnings (or earnings opportunities), child labor may be positively correlated with improvements in economic status (e.g. Parsons and Goldin 1989; Psacharopoulos 1997, or Bhalotra and Heady 2000). ${ }^{4}$ Moreover, several papers have examined episodes of growth that coincide with periods of increases in schooling or declines in child labor and identified factors such as changes in technology (Levy 1985, Brown and Peter 1992), the returns to schooling (Foster and Rosenzweig 1996), or policy (Acemoglu and Angrist 1999) that are correlated with both improving economic status and child labor or schooling.

If correct, the hypothesis that increases in income will not result in substantial declines in child labor has important implications for the way economists think about the amelioration of child labor and the consequences of globalization and economic growth. First, to the extent that policy desires to reduce child labor, if child labor supply does not decline with income, then reduction in child labor may require a social policy targeted specifically at child labor. This

\footnotetext{
${ }^{3}$ One exception is the recent literature that has appeared subsequent to this paper that considers how child labor supply is affected by economic shocks (e.g. Beegle, Dehejia, and Gatti 2003a, Guarcello, Mealli, and Rosati 2003, Yang 2003) which generally finds child labor supply to be responsive to unanticipated changes in the household's environment. While the response of child labor supply to shocks depends on the operation of credit and insurance markets, there may also be an income component in these studies.

${ }^{4} \mathrm{~A}$ third interpretation is the Ben-Porath (1967) model where educational investments (and then child labor supply) are determined by weighing the present discounted value of schooling against its opportunity cost. If the equilibrium investment decision does not vary with economic status, then child labor might not vary either. I have not seen this point raised as an interpretation of a weak cross-sectional association between child labor and living standards.
} 
viewpoint is consistent with the "human development" approach of formulating policy based on targeting various non-financial measures of well-being as discussed in Anand and Ravallion (1993). Second, as is often claimed in the popular debate over globalization, the promotion of growth does not imply the elimination in child labor. In fact, to the extent that economic growth is associated with employment growth, policies that foster economic growth could spur increases in child labor. This issue becomes particularly relevant in the debate over trade liberalization where the principal aim of the policy is the expansion of economic activity.

The relationship between improvements in economic status and child labor is examined in this study using household level panel data from the 1993 and 1998 Vietnam Living Standards Surveys (General Statistical Office 1994 and 1999). This dataset is novel both in the large number of households that it interviews in each round of the panel and in its collection of detailed child labor data in a consistent manner over time. The attraction of the panel is that by observing the same households over time, it is easy to evaluate assertions that child labor supply is invariant to the household's economic environment because of time invariant cultural norms or parental attitudes which are impossible to test in the cross-section as these norms and attitudes are unobserved heterogeneity. In fact, the data reveal dramatic, nearly 30 percent, declines in child labor in the same set of households over a 5 year period.

Moreover, the panel nature of the data makes it straightforward to separate changes in child labor supply over time that are attributable to exogenous changes in the technology, policy, or market environment from factors driving improving economic status. These environmental changes occur through time, and thus are not present in the cross-sectional relationship between child labor and economic status. Thus, this study uses the relationship between child labor and economic status in the first round of the panel (1993) to predict the observed declines in child 
labor through time (between 1993 and 1998) using information on improvements in economic status through time. Of course while technology, policy, or price changes that are concurrent with growth are not present in the cross section, there are a vast set of differences between households that vary in their economic status other than just economic status. To the extent that cross-sectional variation in child labor reflects these differences that are not determined by economic status, the cross-sectional relationship between child labor and economic status will not be able to predict changes in child labor using observed improvements in economic status. In fact, the data suggest that 60 percent of the observed changes in child labor through time can be explained in this manner by improvements in economic status. In considering population subgroups, improvements in economic status better predict declines in child labor for boys than for girls, in large households than in small, and for lower secondary school age children. In addition to explaining declines in child labor, economic status improvements appear to predict a large portion of the increase in school enrollment for children in this lower secondary school age group.

Finally, the size of the panel dataset is large enough that it is possible to employ nonparametric techniques in analyzing the relationship between declines in child labor and improvements in economic status. Non-parametric techniques are particularly useful for studying the relationship between child labor and economic status, because there are strong theoretical reasons to expect the relationship between the two to be highly non-linear. In the Basu and Van (1998) model, children work only when their income is necessary to meet subsistence needs. Thus, the relationship between child labor and economic status should be flat until households begin to meet subsistence needs, then child labor should decline rapidly. In fact, the data reveal dramatic non-linearity in the relationship between child labor and economic 
status in the neighborhood of the poverty line. The importance of non-linearity may explain why many other studies fail to find a relationship between child labor and economic status if linear regression techniques average over regions where child labor is and is not elastic. In the Vietnamese data, child labor declines dramatically at the poverty line in the 1993 cross-section, and improvements in economic status can explain 80 percent of the decline in child labor in households that exit poverty.

This paper is organized as follows. The next section of the paper discusses the data and describes the changes in economic status and child labor that occur in Vietnam. Section 3 begins with descriptive evidence on the relationship between increasing economic status and declining child labor. Part 2 of section 3 develops the nonparametric decomposition that will be used in this study in the context of the Basu and Van (1998) model. Part 3 of section 3 describes and implements the nonparametric decomposition. Section 4 discusses the interpretation of the decomposition and considers how substantive non-linearity is in this study's analysis by comparing the nonparametric framework to a more standard, linear decomposition. Section 5 extends the decomposition by looking at several gender, age, and household size subgroups. ${ }^{5}$ Section 6 places the results of this paper in the broader literature, discusses several important caveats, and assesses the extent to which the results of this paper might generalize.

\section{Data Description}

I explore the link between economic status improvements and child labor using data from the 3,347 panel households with children between the ages of 6 and 15 in the Vietnam Living Standards Surveys (VLSS). The first round of the VLSS took place between September 1992 and October 1993, and the second round of the VLSS took place between December 1997 and

\footnotetext{
${ }^{5}$ Appendix 1 controls for differences in child labor across these different characteristics simultaneously by developing a semi-parametric version of the methodology in section 3. Appendix 2 considers whether different assumptions about the calculation of adult equivalence scales affect the predictive power of economic status.
} 
December 1998 (World Bank 2000). ${ }^{6}$ The VLSS is a multi-purpose household survey, collecting detailed information on the activities of household members as well as household expenditures. To measure household economic status, I consider the logarithm of per capita expenditure. ${ }^{7}$ The calculation of the expenditure aggregate for the VLSS is described in World Bank (2000). I use a definition of expenditure that is comparable between the two rounds of the VLSS. ${ }^{8}$ The expenditure measure is defined as annual expenditure and includes both household purchases and imputed values of home produced and traded goods. ${ }^{9}$ Food constitutes 61 percent of the total household budget in 1993 and 58 percent in 1998.

Households are much better off in 1998 than in 1993. Figure 1 pictures the distribution of the logarithm of per capita expenditure for all VLSS households in 1993 and 1998. The two distributions are kernel estimates of the density of logarithm of per capita expenditure. There are two vertical lines in figure 1. The left most line is the estimated cost of acquiring enough food to consume 2100 calories per day (with no allowance for non-food expenditures), approximately USD $\$ 65$ per person per year. The second line adds to the 2100 calorie per day line an estimate of the cost of nonfood necessities. It is the official 1993 poverty line (approximately USD \$106

\footnotetext{
${ }^{6}$ Glewwe and Nguyen (2004) discuss attrition in the panel and conclude that the panel appears to be approximately nationally representative. The panel recaptured 89.6 percent of its targeted households. However, the reader should be cautioned that the experiences of panel households might not generalize to the nation as a whole.

${ }^{7}$ I divide total expenditure by household size to get total expenditure per capita. Implicit in dividing by household size is a set of strong assumptions about the costs of children and economies of scale within the household (Deaton and Paxson 1998). I consider this issue of economies of scale in greater detail in Appendix 2. There are two justifications for looking at expenditure rather than income. First, most households do not participate exclusively in formal labor markets. Hence, calculating income is difficult. Second, while income is variable, households may try to smooth consumption (represented in the VLSS by expenditure) through time. Evidence such as Paxson (1993) suggests that expenditure varies less than income, and the life cycle hypothesis suggests expenditure better reflects the household's current beliefs about its long-term economic status.

${ }^{8}$ Expenditure includes both purchased goods and the imputed value of home production that is consumed in the household. Durable goods are not included in total expenditure, but an imputed rental value of durables is included. Expenditure is deflated so that expenditure in both 1993 and 1998 is expressed in hundreds of January 1998 Dongs.

${ }^{9}$ Measurement error in total expenditure is a chronic problem in expenditure surveys such as the VLSS. The VLSS attempts to minimize measurement error by attaining expenditure information separately on 64 food items and 86 nonfood items. However, measurement error in total expenditure may hurt the ability of apparent per capita expenditure improvements to predict declines in child labor, because some of the "improvements" might stem from measurement error rather than changes in the household's economic environment.
} 
per person per year). The calculation of both lines is described in the Vietnam Development Report 2000.

The dramatic improvement in economic status in Vietnam during the 1990s is evident in figure 1. Despite being deflated to be in the same units, the mass of the entire distribution of per capita expenditure is shifted right in 1998. Large declines in the population living in households that can afford 2100 calories per day and declines in the overall poverty rate accompany this dramatic improvement in the per capita expenditure distribution. 25 percent of the population in 1993 is in households with per capita expenditures below what is necessary to purchase 2100 calories per day. Only 8 percent of the population has 1998 expenditures below this level. 58 percent of the population is in households below the poverty line in 1993 while 33 percent of all households in 1998 report expenditures below the 1993 poverty line. The shape of the two densities in figure 1 is similar. This indicates that overall inequality is largely unchanged. The aim of this paper is to relate this shift in the per capita expenditure distribution to changes in child labor.

To discuss the link between economic status and child labor, I focus on the economic activities of children between the ages of six and fifteen that are household members. I restrict my sample to VLSS panel households, but I do not limit my analysis to children who reappear in the survey in both rounds. I begin with children aged six, because the VLSS does not collect data on the economic activities of children under six. I choose fifteen as an upper bound, because that is a common upper bound in many international conventions on child labor. In this study, a child engages in child labor if the child worked during the last week in agriculture ("agr"), in a family business ("fam bus"), or outside of the household for pay ("outside house"). The VLSS collects information on each of these types of activities separately. Table 1 presents 
child participation rates by age and year in each of these categories separately and aggregated together (labeled "work").

Most working children participate in agriculture. This is true at every age and in both years. In general, the probability that a child works increases in age. Not surprisingly, the probability that a child works falls more for older children than younger children over time. This reflects the fact that participation rates are higher for older children in 1993, and the declines in child labor over time are largest for these older children in agriculture. At every age and in every type of work, participation rates either do not change or decline between 1993 and 1998 in Vietnam.

\section{Explaining Child Labor Declines with Improving Expenditures}

\subsection{Tabulations of Child Labor by Expenditure Quintile}

Table 2 previews the relationship between per capita expenditure and child labor that I

explore in this paper. I split the sample into quintiles of per capita expenditure in 1993. The left side of table 2 contains the probability a child works in 1993 in each of the work categories from table 1. The right side of table 2 contains the 1998 data.

The negative relationship between child labor and household expenditure is evident in column one of table 2 . The probability that a child works declines with each quintile in 1993 from a high of 39 percent of children 6-15 in the poorest quintile to 16 percent of children in the top quintile in 1993. This decline in child labor with improvements in per capita expenditure appears in both work outside of the household and for work in agriculture. There is a noticeable exception in work for a family business as wealthier households are more likely to own a family business than are poor households. Thus, the data on participation in a family business confound 
the fact that the opportunity to work in a family business is increasing in per capita expenditure with any link between per capita expenditure and the household's desired child labor supply.

The quintiles for both years of data in table 2 are quintiles of expenditure per capita in 1993. Hence, the same households are in the same quintile in both years. In every type of work and every quintile, the probability that a child works is lower in 1998 than in 1993. In general, the relationship between per capita expenditure in 1993 and the size of the decline in child labor that occurs between 1993 and 1998 is unclear. In percentage terms, participation in any type of work declines more in richer households than in poorer households, but this reflects the lower participation rates in rich households in 1993 rather than the magnitude of the decline in child labor. In magnitude (rather than percentage terms), the largest decline in participation in any type of work is in agricultural work for households in the second to poorest quintile.

In the decomposition that follows economic status improvements appear to be the primary reason for declines in child labor in this group. While most households experience improvements in per capita expenditure (Glewwe and Nguyen 2002), the decomposition below suggests that the improvements in economic status for this second quintile group are large enough to significantly reduce the need for children to work. Economic status does not increase enough in the poorest quintile to affect a dramatic decline in child labor, and in richer households, perhaps factors other than poverty drive child labor supply.

\subsection{Theoretical motivation}

The decomposition employed in this study follows from a simple adaptation of Basu and Van's (1998) model of child labor supply. ${ }^{10}$ Let $s_{i}$ denote the expenditure necessary for household $i$ to be able to make its desired investments (nutritional, educational, etc.) in its

\footnotetext{
${ }^{10}$ In this discussion, I abstract from the question of how inequality affects child labor supply. See Ranjan (2001) and Rogers and Swinnerton (2001) for in depth discussions.
} 
members, household i's subsistence expenditure. In the population, households differ in what they perceive as the necessary level of household expenditure at which children no longer need to work, s. The shape of the $s$ distribution is an empirical question, but in the present discussion $s$ has a continuous, $\log$ concave distribution such as the lognormal with some positive density throughout the population. In the language of this study, changes through time in technology, policy, the returns to education, relative prices, etc. are reflected in changes in the distribution of s. Thus, the objective of the empirical work is to see how much of the decline in child labor can be explained by holding the distribution of $s$ fixed.

In order to simplify the present discussion, assume the household consists of one parent and one child. The parent decides whether the child works, $y \in\{0,1\}$. Parental preferences are defined over household per capita expenditure $x$ and child labor supply. Basu and Van's luxury axiom implies that, for all $\delta>0$ :

$$
\begin{aligned}
& \left(x_{i}, 0\right) \succ\left(x_{i}+\delta, 1\right) \text { if } x_{i} \geq s_{i} \\
& \text { and }\left(x_{i}, 0\right) \prec\left(x_{i}+\delta, 1\right) \text { if } x_{i}<s_{i}
\end{aligned} .
$$

Without child labor, parents can attain some maximum household income $m_{i} . m_{i}$ can be interpreted as a function of the household's endowments when children do not work whereas $s$ reflects factors that affect the household's perceived subsistence needs such as local prices, policies, or other environmental factors. Note that changes in both observed expenditures and child labor are jointly determined by the household's ability to translate its endowment to income. Child labor adds an additional increment $w$ to household income. For simplicity, $w$ does not vary across households. The household's budget set is: $2 x_{i} \leq y_{i} w+m_{i}$ and the solution to the household's maximization problem gives child labor supply as: 


$$
y_{i}=\left\{\begin{array}{l}
0 \text { if } m_{i} \geq 2 s_{i} \\
1 \text { if } m_{i}<2 s_{i}
\end{array} .\right.
$$

Because $s$ varies across households and has positive density throughout the population, for any level of per capita expenditure, I observe households where children work and children do not work. In households without child labor, $m_{i} \geq 2 s_{i}$, and per capita expenditure is $m_{i} / 2$. In households with child labor, $m_{i}<2 s_{i}$, and per capita expenditure is $\left(w+m_{i}\right) / 2$.

In this model, the incidence of child labor depends on the joint distribution of $s$ and $m$. However, conditional on a given level of expenditure per capita, the incidence of child labor depends on the conditional distribution of $s$ given $m$. This calculation is straightforward:

$$
\begin{aligned}
E[y \mid x] & =0 * \operatorname{Pr}(m \geq 2 s \mid m)+1 * \operatorname{Pr}(m<2 s \mid m+w) \\
& =\operatorname{Pr}(m<2 s \mid m+w)=\operatorname{Pr}(m<2 s \mid m) \\
& =\operatorname{Pr}\left(s>\frac{m}{2} \mid m\right)=\int_{m / 2}^{\infty} g(s \mid m) d s
\end{aligned}
$$

Thus, the expectation of child labor given per capita expenditure depends on distribution of subsistence needs given the value of the household's endowment.

In the present context, households are observed twice. Let subscripts 1 and 2 denote observations from the first and second round of the panel respectively. The change in child labor participation rates between 1993 and 1998 observed at point $x_{1}$ in the baseline (1993) per capita expenditure distribution is then: $E\left[y_{1} \mid x_{1}\right]-E\left[y_{2} \mid x_{1}\right]$. Following (1), define:

$$
\text { (3) } \quad E\left[y_{2} \mid x_{1}\right]=\int_{m_{1} / 2}^{\infty} h\left(s \mid m_{1}\right) d s \text {. }
$$


The change in child labor participation rates is then attributable to the difference between $g\left(s \mid m_{1}\right)$ and $h\left(s \mid m_{1}\right)$. Two factors are responsible for any differences between the two densities. First, the value of the household's income absent child labor (or alternatively the income attainable from the value of the household's endowment) may change. That is, $m_{1}$ differs from $m_{2}$. Second, the distribution of subsistence needs changes. For example, a policy change could lower the cost of schooling. Hence, the household income at which children no longer needed to work would decline. This would affect child labor participation rates even if the value of household endowments remained fixed. The aim of the decomposition in the paper is to estimate how important changes in the value of household endowments are in the observed declines in child labor. To do this, the conditional distribution of $s$ given $m$ needs to be fixed.

Denote $\hat{x}_{2}$ as the expected per capita expenditure in 1998 expected at point $x_{1}$ in the baseline (1993) per capita expenditure distribution: $\hat{x}_{2}=E\left[x_{2} \mid x_{1}\right]$. The change in the child participation rate at $x_{1}$ that would be expected based on improvements in per capita expenditure alone is $E\left[y_{1} \mid x_{1}\right]-E\left[y_{1} \mid \hat{x}_{2}\right]$ where $E\left[y_{1} \mid \hat{x}_{2}\right]=\int_{\hat{m}_{2} / 2}^{\infty} g\left(s \mid \hat{m}_{2}\right) d s$. Thus the calculation of how important improvements in per capita expenditure are in changes in child labor participation rates is straightforward. First, the association between child labor and per capita expenditures in the cross-section is computed using nonparametric regression. The predicted child labor participation rate based on improvements in per capita expenditure then uses this relationship to estimate the child labor supply expected in the second round based on the observed improvements in per capita expenditure.

\subsection{A Nonparametric Decomposition}


In this section, I describe how I examine the relationship between child labor and household economic status. Child labor and economic status are jointly determined so the conditional expectations computed in this study do not have causal interpretations. A straightforward application of the Blinder - Oaxaca methodology to the present case would entail regressing child labor in 1993 on per capita expenditure in 1993, then using the estimated regression coefficient to predict child labor in 1998. I consider this approach at the end of this section. However, as discussed in the introduction and the previous subsection, non-linearity in the relationship between per capita expenditure and child labor may be very important. Thus, this study uses non-parametric techniques to compute child labor participation rates (or the probability that "work" equals one times 100) throughout the household per capita expenditure distribution: $E[Y \mid X]=\pi(X)$. Per capita expenditure $(X)$ is the logarithm of total per capita expenditure, and $Y$ is the corresponding child labor participation rate. $\pi(X)$ is estimated with a local-linear regression technique so the estimate of $\pi(x)$ is the predicted value from the local regression at $x$ (Fan and Gijbels 1995 and Deaton 1997). ${ }^{11}$

I begin by estimating the relationship between child labor and the logarithm of per capita expenditure in 1993. Figure 2 contains this regression for panel households with children 6-15 in

\footnotetext{
${ }^{11}$ The bandwidth selection procedure in figures 2-4 works as follows. I pick a bandwidth for the point on the per capita expenditure grid with the greatest density. I then compute a bandwidth for each point on the per capita expenditure grid by multiplying this bandwidth by the square of the inverse of the estimated density (relative to the greatest observed density). The advantage of this weighting is that the bandwidth used in estimating the expected incidence of child labor is greater for parts of the per capita expenditure distribution with less mass. The base bandwidth (at the point of greatest density) is selected by a cross-validation procedure that works as follows. I consider a grid of possible bandwidths. For each bandwidth on the grid, I use the density based procedure just described to compute a bandwidth for each point on the per capita expenditure grid. I then compute the meanintegrated squared error across all observations. I repeat this procedure across the range of bandwidths, and select the bandwidth that minimizes mean-integrated squared error. Subsequent to figure 4, bandwidths are chosen to match the degree of smoothing that appears in figure 4.
} 
1993. 90 percent confidence bands (the dotted lines) are also pictured in figure $2 .{ }^{12}$ With nonparametric regression, the ability to compute participation rates conditional on per capita expenditure is limited to regions of the per capita expenditure distribution where there is support. In the bottom 5 percent of the per capita expenditure distribution, the standard deviation of the logarithm of per capita expenditure is almost six times that of the next 5 percent of the population. Because of this diffusion, the local regression techniques in this paper do not perform well. A similar problem plagues the top of the distribution 1993. Hence, the analysis of this paper focuses on households with a logarithm of per capita expenditure above 6.51 and below 8.28. 94 percent of all working children in 1993 are within this range.

The probability a child works declines in per capita expenditure. There are two important parts of figure 2. First, in the poorest households with per capita expenditure below that necessary to purchases 2100 calories per day, child labor appears fairly inelastic with respect to per capita expenditure. A flat or even increasing relationship is consistent with the indicated confidence bounds. If there is any upward slope in this range, it may reflect the contribution of child labor to household per capita expenditure. However, around the 2100 calorie per day line, child labor begins to decline with expenditure. This corresponds to a per capita expenditure of about USD $\$ 65$ per person per year. The second important part of figure 2 is around the poverty line. There, the rate of decline in participation rates appears to increase before leveling off slightly at around the equivalent of USD $\$ 192$ per person per year ( 7.7 in figure 2 ). Thus, the picture in figure 2 is consistent with the framework elucidated in the previous section. Below

\footnotetext{
${ }^{12}$ I estimate standard errors for the regression function by bootstrapping. The VLSS panel consists of 3347 households with children drawn from 117 communes. Since there is likely significant homogeneity in child labor within communes, the effective sample size is less than 3436. My bootstrapping procedure preserves this feature of the sample design by sampling communes rather than households, then retaining all of the households within the selected commune. I generate 100 such bootstrap samples and re-estimate the local regression for each draw of the bootstrap.
} 
subsistence, there is little evidence of a link between child labor and per capita expenditure. Above the 2100 calorie per day line, households begin to have per capita expenditures above the household's perception of subsistence, and the number of households with subsistence levels in the neighborhood of the poverty line is large. Thus, the decline in child labor accelerates in the neighborhood of the poverty line.

The relationship between child labor and the logarithm of per capita expenditure in figure 2 indicates how child labor participation co-varies with per capita expenditure at a single point in time. This mapping summarizes all of the mechanisms that cause child labor to vary with per capita expenditure in the 1993 cross-section. The aim of this decomposition is to identify how much of the observed decline in child labor is associated with improvements in economic status (that is, the process of moving across the per capita expenditure distribution in figure 2) as opposed to other time-varying factors associated with growth that are not directly related to differences in economic status across households. Thus, the explanatory power of improvements in per capita expenditure is computed by using figure 2 to predict child labor in 1998.

To do this, the decomposition proceeds in three steps. First, the relationship between child labor and per capita expenditure is mapped in the 1993 dataset (figure 2):

$$
E\left[y_{i, 93} \mid X_{i, 93}\right]=\pi_{93}\left(X_{i, 93}\right)
$$

This conditional expectation is used to predict the decline in child labor through time. In order, to use this mapping of the link between per capita expenditure variation and child labor, I need to know how much per capita expenditures improve through time at each point of the 1993 per capita expenditure distribution. This is a straightforward calculation:

$$
E\left[X_{i, 98} \mid X_{i, 93}\right]=\theta_{98}\left(X_{i, 93}\right)
$$

This regression appears in figure 3: 
While figure 1 indicates that the distribution of per capita expenditure shifts forward between 1993 and 1998, figure 3 shows that within household changes are generally large and positive. The straight line is the forty-five degree line where per capita expenditure in 1993 equals per capita expenditure in 1998. Poorer households experience larger increases in per capita expenditure than do richer households. The observation that poorer households experience larger increases in expenditure per capita may in part reflect measurement error. Glewwe and Nguyen (2004) find that estimates of economic mobility in Vietnam are substantially reduced when they correct for measurement error in expenditure per capita. In the present case, this likely hurts the predictive power of the decomposition. If these increases in per capita expenditure are noise, then they would not predict declines in child labor.

The third step in the decomposition is to use the prediction of per capita expenditure improvements in (5) to predict child labor in 1998 from the relationship between per capita expenditure and child labor defined by (4). This can be written:

$$
\bar{y}_{i, 98}=\pi_{93}\left(\theta_{98}\left(X_{i, 93}\right)\right)
$$

I compare this predicted child labor to the observed child labor in 1998. This is calculated by a regression of child labor in 1998 on per capita expenditure in 1993:

$$
E\left[y_{i, 98} \mid X_{i, 93}\right]=\pi_{98}\left(X_{i, 93}\right) .
$$

This approach differs from a standard decomposition in two ways. First, it is entirely nonparametric, so it is not just calculating the decomposition at the sample mean. Second, it makes use of the panel structure of the data. At any given $x$ for the decomposition, I include the same households. Hence, all of the variation observed in this decomposition comes from within household changes in child labor. Parental callousness, social norms, or other models that posit child labor to be a household fixed effect would thus predict no changes in child labor, and the 
shift in the per capita expenditure distribution should not explain any changes in child labor that are observed.

Figure 4 presents the results of this decomposition analysis. ${ }^{13}$ The line marked 1993 contains the 1993 cross-sectional relationship observed in figure 2. It appears flatter in this figure because of the change in the scale of the vertical axis. The line marked 1998 contains the expected child labor in 1998 by per capita expenditure in 1993 (eq. 5). The line marked predicted is the output of the calculation in (6) and contains the predicted child labor in 1998 based on the relationship between child labor and per capita expenditure observed in 1993 (figure 2). The (dotted line) 90 percent confidence bands in this picture are for the predicted line. There are two vertical lines in figure 4 . The right-most vertical line is the 1993 poverty line. The left-most vertical line indicates the minimum 1993 expenditure per capita for households with a per capita expenditure in 1998 above the poverty line. Thus, all children in households between those two vertical lines move from below the poverty line in 1993 to above the poverty line in 1998. I refer to these households as poverty exiting households in the remainder of the paper.

The cross-sectional relationship between child labor and per capita expenditure in 1993 does a remarkable job of predicting child labor in 1998 based on per capita expenditure in 1998. Overall 59 percent of the observed declines in child labor can be explained by the 1993 mapping of the association between per capita expenditure and child labor supply. ${ }^{14}$ The strongest

\footnotetext{
${ }^{13}$ Because the 1993 mapping (4) encounters support problems with the logarithm of per capita expenditure in 1993 above 8.28 , the 1998 predicted incidence of child labor can only be computed for regions where the predicted per capita expenditure in 1998 is at or below 8.28. Thus, the decomposition is limited to households with a 1993 logarithm of per capita expenditure of 8.07 or less, because the predicted per capita expenditure in 1998 for households with a $1993 \mathrm{log}$ pcx of 8.07 is 8.28. All remaining figures are then pictured with a range of 6.51 to 8.07.

${ }^{14}$ I calculate the fraction of the decline in child labor that can be explained by living standards improvements by calculating the fraction of the decline in child labor explained by the predicted line for each point on the per capita expenditure grid. I then take the weighted average of these fractions using kernel density estimates of the 1993 per capita expenditure distribution.
} 
predictive power comes for households that move from below the poverty line in 1993 to above the poverty line in 1998. For children in these poverty exiting households, 80 percent of the observed, approximately 13 point (or 36 percent) decline in child labor can be explained by improvements in per capita expenditure. If the poverty line is a meaningful measure of household perceptions of subsistence levels, the model of the previous section would predict that per capita expenditure improvements should have the most predictive power for this poverty exiting group. The weakest predictive power of improvements in per capita expenditure is for households above the poverty line in 1993. In these households, improvements in per capita expenditure explain less than half of the observed decline in child labor. There are two potential explanations for this. First, children may not be working because of poverty in these households. Hence, I would not expect per capita expenditure to explain inter-temporal variation in child labor. Second, mechanically, these households achieve per capita expenditures that are so high in 1998 that I do not have the data in 1993 with which to make accurate projections of what child labor should look like (based on cross-sectional variation in child labor and per capita expenditure) in households that are so well off.

\section{Interpretation}

\subsection{Alternative explanations of the results for households that exit poverty}

The finding that economic status improvements can explain declines in child labor in households that exit poverty is consistent with the Basu and Van framework articulated in section 3.2 where children work to help families meet subsistence needs. ${ }^{15}$ However, it is possible to explain the findings observed in Figure 4 in a model where child labor is not a bad in parental preferences. For example, suppose the mapping between child labor supply and per

\footnotetext{
${ }^{15}$ An observationally equivalent explanation would come from a model with continuous child labor supply and an Engel curve for food in family preferences. I am grateful to Andrew Foster for pointing this out.
} 
capita expenditures in 1993 reflects differences across communities in local labor demand. This explanation is possible, because there is significant geographic clustering in per capita expenditures. Moreover, suppose that the communities in which households exit poverty between 1993 and 1998 experience a shock to child labor demand that reduces child labor to levels that coincidentally match those observed in households above the poverty line in 1993. This model might generate a result such as Figure 4 without any impact of improvements in economic status on child labor.

Two pieces of evidence in the data suggest that this spurious correlation explanation may be incorrect. First, the relationship between per capita expenditures and child labor supply in 1993 in Figure 2 does not seem consistent with this story. Child labor does not appear to vary with per capita expenditures until households can meet their food needs, and it then declines dramatically. It would be surprising if employment opportunities began to decline at the same point that households became wealthy enough to afford their basic needs. In fact, a number of authors have suggested that the employment opportunities for children are greater in wealthier households and communities because of greater economic activity (e.g. Bhalotra and Heady 2000, Basu and Tzannatos 2004, Edmonds and Turk 2004). Thus, if child labor were entirely demand driven, the cross-sectional relationship should be the opposite of that in Figure 2. Second, in Appendix 1, I specify a semi-parametric version of the present decomposition that can be modified to include community fixed effects. With community fixed effects, the association between child labor and per capita expenditure in 1993 is identified by within community variation in per capita expenditures. With this adapted methodology, I find a similar relationship to what is observed without community fixed effects. These two pieces of evidence are inconsistent with a story based on labor demand alone. 
However, a modification to this spurious correlation story would be that the relationship in Figure 2 reflects variation in tastes for child labor that have nothing to do with the causal relation between economic status and child labor, and by coincidence, other changes in the household's environment affect declines in child labor that happen to correspond to child labor participation rates that match the improvements in per capita expenditures observed in on average in poverty exiting households in 1998. I can exploit the heterogeneity in the changes in per capita expenditure that occur across households in a neighborhood of a given per capita expenditure in order to consider this alternative explanation of the findings. I bifurcate the sample into households that experience increases and decreases in per capita expenditure between 1993 and $1998 .{ }^{16}$ If the changes in child labor are unrelated to the household's improvement or decline in per capita expenditure, then the observed changes in child labor should not depend on whether a household's real per capita expenditure increases or decreases between 1993 and 1998.

Figure 5 shows that the declines in child labor occur in households that experience increases in per capita expenditure among the households that exit poverty between 1993 and 1998. Figure 5 displays the decline in participation rates in market work (a positive number is a decline in child labor between 1993 and 1998) against per capita expenditure in 1993 for households that experience increases in real per capita expenditures and (separately) households that experience decreases in real per capita expenditures between 1993 and 1998. Confidence bounds are pictured for households whose per capita expenditures increase. The sample size is small for households with declines in per capita expenditures. Thus the confidence bounds are very large for that relationship and generally overlap the confidence interval for households that

\footnotetext{
${ }^{16}$ There is an obvious endogeneity problem in this bifurcation. If a child exogenously stops working, then per capita expenditures may decline. Hence, it is plausible that declines in child labor will be concentrated in households that experience declines in per capita expenditure
} 
experience increases in per capita expenditures. That said, throughout the range of households where per capita expenditure improvements are most successful in explaining declines in child labor, the declines in child labor are in the households that actually experience the improvements in per capita expenditures. In fact, child labor is generally increasing in households that become poorer between 1993 and 1998. Hence, the spurious correlation explanation for the explanatory power of economic status improvements does not appear consistent with the data.

\subsection{The significance of non-parametric methods}

Non-linearity is clearly important in the relationship between economic status and child labor. The basis for the decomposition in this study is the relationship in Figure 2 which is highly non-linear. The obvious question is how much additional explanatory power is coming from the use of nonparametric techniques relative to the standard linear regression techniques that are ubiquitous in most decompositions. To compare the two methods, I run a linear regression of the work indicator on the log of expenditure per capita for the 1993 data: $y_{i, 93}=\beta_{0,93}+\beta_{1,93} X_{i, 93}+\in_{i, 98} \cdot{ }^{17}$ At any given point, $x_{93}$, I can compute the expected child labor in 1993 as $E\left[\hat{y}_{93} \mid x_{93}\right]=\beta_{0,93}+\beta_{1,93} X_{93}$. This is comparable to the calculation in (4). I can compute the linear analogue to (6) as $E\left[\bar{y}_{98} \mid x_{93}\right]=\beta_{0,93}+\beta_{1,93} E\left[x_{98} \mid x_{93}\right]$ where I estimate $E\left[x_{98} \mid x_{93}\right]$ using the local regression techniques described above. Thus at any point $x_{93}$, the fraction of the decline in child labor that can be explained by improvements in per capita expenditure is:

$$
\frac{E\left[\bar{y}_{98} \mid x_{93}\right]-E\left[\hat{y}_{93} \mid x_{93}\right]}{E\left[y_{98} \mid x_{93}\right]-E\left[y_{93} \mid x_{93}\right]}
$$

The two expectations in the denominator are the nonparametric estimates from section 3.3. With this approach, I compute the fraction of the reduction in child labor that can be explained by

\footnotetext{
${ }^{17}$ This regression estimates $\beta_{1,93}$ as -0.13 ; the t-statistics is 12.08 for the test of the null-hypothesis that $\beta_{1,93}$ is 0 .
} 
linear regression for various parts of the per capita expenditure distribution. These results are in table 3. I use kernel weights that put greater weight on values of per capita expenditure with a greater density in computing the explanatory power of the linear regression.

The standard linear model explains a remarkable fraction of the decline in child labor. The first column of table 3 contains the results from the linear regression, and the second column contains the equivalent of (8) calculated by replacing the linear expectations in the numerator with the nonparametric expectations calculated in section 3.3 (figure 4). In the relatively dispersed bottom quartile of the population, the linear estimator does better than the nonparametric estimator, because the linear functional form solves the problems of low density that plague the nonparametric regression. In the rest of the distribution, the local regression techniques developed in this paper have greater explanatory power.

The difference between the local and linear results is greatest for households that exit poverty. While the local regression techniques explain 80 percent of the decline in child labor for this group, linear techniques explain only 51 percent of this group's decline. The reason for this large difference between techniques in predicting declines in child labor for poverty exiting households is evident in figure 2. There is a distinct change in slope and acceleration in the decline in child labor associated with per capita expenditure for households in the neighborhood of the poverty line in the local regression line for 1993 in figure 2 . In households that exit poverty between 1993 and 1998, per capita expenditure improve across this region of dramatic declines in child labor. The linear regression misses this region of rapid decline in child labor, and hence dramatically under-predicts the decline in child labor that occurs in households that move out of poverty.

\section{Results within Population Subgroups}


In the previous sections, I considered the ability of economic status improvements to explain declines in child labor for all children 6-15 in panel households of the VLSS. However, the explanatory power of per capita expenditure improvements may vary with child and household characteristics. ${ }^{18}$ Both the opportunity cost of child time not spent working and the probability of school enrollment varies with age and gender. Thus, I split the sample by gender and by age. Additional expenditure might affect smaller households differently than big households both becomes of economies in scale in household production and because of differing labor demands of large and small households. Thus, I also stratify the sample by household size. ${ }^{19}$ In Appendix 1, I also consider the explanatory power of per capita expenditure when I control for gender, age, and household simultaneously. This requires adapting the approach in section 3 to a semiparametric framework. In Appendix 2, I explore the role of different assumptions about child costs and economies of scale in the household in my results.

\subsection{Gender}

In Vietnam, there appear to be differences in the types of work performed by boys and girls (Edmonds and Turk 2002). Girls are more likely than boys to work in most types of work. In addition to the types of market work focused on here, girls typically supplement their work in agriculture with additional work within the household such as cooking, cleaning, caretaking, or collecting wood and water. Even within the types of work considered here, girls and boys may perform different tasks. Further, there may be gender-based differences in the opportunity cost of child labor if schooling trades off with child labor and parents expect to capture a greater

\footnotetext{
${ }^{18}$ The variation across child and household attributes examined in this section could be incorporated into the model of section 3.2 by allowing the distribution of $s$ given $m$ to vary either by child or by household characteristics.

${ }^{19}$ I would like to be able to consider age-gender-household size groupings instead of stratifying by each characteristic separately. However, the VLSS sample size is too small for such disaggregating.
} 
return to schooling from boys. Hence, it is possible that boys and girls may not be equally affected by improvements in economic status.

Per capita expenditure improvements better explain declines in child labor for boys than for girls. Figure 6 presents the results of re-estimating each of the regressions (2) - (5) separately for boys and girls. The lines are marked as described in the discussion around figure 4 and the dotted lines represent confidence bands for the predicted line (6). Figure 6A contains the results for girls; Figure $6 \mathrm{~B}$ contains the results for boys.

The contrast between boys and girls in the ability of per capita expenditure improvements to explain declines in child labor is striking. First, focusing on the 1993 cross-sectional relationship, child labor for boys drops more dramatically with per capita expenditure than it does for girls. In fact, the most dramatic decline in child labor for boys appears to take place at about the level of annual expenditure that the Vietnam Development Report contends is necessary to purchase 2100 calories per day in 1993 (7.0 on the log scale; USD \$65). For girls, the relationship between child labor and per capita expenditure is less clear until per capita expenditures are above the poverty line. A common anecdote in Vietnam is that parent's perceive a greater return to educating boys than girls, so that girls are much more likely to work than boys (Save the Children 1997). This could imply that, in a household, the presence of boys working is more apt to be driven by poverty and therefore male child labor varies more with per capita expenditure in the cross-section.

Second, improvements in per capita expenditure explain a larger fraction of the observed declined in child labor experienced by boys than that experience by girls. Table 4 summarizes the explanatory power of per capita expenditure improvements for all of the demographic subgroups consider in this paper and for various parts of the per capita expenditure distribution. 
Overall, per capita expenditure improvements can explain 69 percent of the observed decline in child labor for boys but only 54 percent of the observed decline for girls. The gender difference in the explanatory power of per capita expenditure improvements is particularly dramatic in the poorest quartile of the population. There, 80 percent of the decline in child labor for boys can be explained by per capita expenditure improvements, but per capita expenditure improvements explain only 49 percent of the decline in child labor for girls in the poorest quartile.

\subsection{Age}

A typical child in Vietnam begins primary school at age 6 and completes primary school at age 11. Most children in Vietnam attend at least some primary school. Secondary school enrollments, both in 1993 and 1998, are generally much lower than primary school enrollment rates. Hence, it makes sense to separate children around age 11. Figure 7A contains the decomposition methodology applied to children age 11 and under.

Participation in child labor is relatively rare (peaking at 26 percent) for children aged 11 and under. Overall improvements in per capita expenditure explain 64 percent of the observed decline in child labor for this age group. As above, per capita expenditure improvements have the greatest explanatory power in households that move from below the poverty line to above it. 85 percent of the decline in child labor for children 6-11 can be explained by improvements per capita expenditure in this group of households that exit poverty.

12 and 13 are important ages for children in Vietnam. The end of primary school (or the end of normal primary school age) is an obvious stopping point for schooling. 50 percent of the adult population in Vietnam has not attended school beyond primary school. Hence, it is in this group that resources may have the largest influence on school enrollment. Figure 7B presents the decomposition for children age 12 and 13. The predictive power of per capita expenditure is 
greatest in the poorest households in the distribution. 99 percent of the decline in child labor in households below the median can be explained by the observed improvements in per capita expenditure. As is typically the case, the methodology dramatically under-predicts the observed decline in child labor in the richest part of the distribution.

Implicit in why I expect a unique effect of economic status on the labor of children ages 12 and 13 is that the reduction in child labor in Figure 7 should be associated with an increase in school enrollment for this age group in 1998. This is apparent in Figure 7C where the procedure described in (2) - (5) is reproduced with school enrollment as the dependent variable. Figure 7C is consistent with parents leaving their children in school longer as their economic status improve. 58 percent of the rise in schooling attendance in the bottom 50 percent of the population can be explained by improvements in per capita expenditure. This finding is consistent with the results in Glewwe and Jacoby (forthcoming) who find that changes in household wealth in Vietnam are associated with changes in the demand of schooling and with Jacoby (1994) who shows that lower income households in Peru withdraw their children from school earlier than do higher income parents.

By age 14, children are closer to being adults in the labor market, and they are further from the end of primary school. Thus, this group is less apt to be affected by changes in per capita expenditure. Figure 7D contains the child labor results for children 14 and 15. This group is very likely to work in 1993 and most kids below the poverty line in 1993 continue to work in 1998. Per capita expenditure improvements can explain 89 percent of the observed decline in child labor in the bottom decile of the per capita expenditure distribution and 79 percent of the observed decline in the bottom 25 percent of the distribution. However, overall, economic status improvements have the weakest predictive power for this older age group of any age group. 


\subsection{Household Size}

Next, I consider how the explanatory power of per capita expenditure varies with household size. The relationship between household size and a household's ability to adjust child labor with economic status improvements is unclear. On the one hand, smaller households have a smaller set of basic needs to be met. Hence, in that sense, it is easier to move an individual child out of work. However, the value of an individual child's contribution to total household resources is likely to be less significant in larger households, because the child will make up a smaller fraction of the household's endowment. In addition, if there are economies of scale within the household, I understate household well-being in 1993 more for larger households. Thus, larger households might start from a better base in 1993 than smaller households. I consider economies of scale assumptions directly in Appendix 2.

For households with children, the modal household size in Vietnam in 1993 is 5 members. 33 percent of households have four members or less. 26 percent have five members, 18 percent have six members, and the remaining 33 percent of households have seven or more members. In the following, I divide children into three different household groups based on the size of their household in 1993. First, I consider households with four or less members. Second, I examine children in households with five or six members. Third, I study children in households with seven or more members. Of course, many household characteristics are correlated with household size, so the differences that I observe across household sizes are not necessarily caused by differences in household size. One obvious problem is that households may choose their number of members based on latent demand for child labor. Hence, child labor may actually cause differences in household size. Despite this problem, comparing child labor across households seems informative. 
Economic status improvements better predict declines in child labor in large households. Figure 8A looks at children in households with four or less members. Expenditure changes do a poor job of explaining the reductions in child labor for this group. Per capita expenditure improvements explain 25 percent of the decline in child labor observed in these small households, and per capita expenditure perform particularly poorly for household that move from below to above the poverty line. Hence, factors other than economic status seem particularly important in the child labor supply decision in these households where child time is a considerable fraction of the household's overall time endowment. Figure 8B considers children in households with 5 or 6 members. Overall, per capita expenditure improvements explain 52 percent of the observed decline in child labor in these medium sized households. As is frequently the case in this study, the best predictive power is for households that move from below to above the poverty line. Figure $8 \mathrm{C}$ contains the results for households with 7 or more members. Overall, 62 percent of the observed decline in child labor in these large households can be explained by per capita expenditure improvements. However, for children in households that move from below to above the poverty line, 95 percent of the observed decline in child labor can be attributed to improvements in per capita expenditure.

\section{Conclusion}

The main finding of this paper is that economic status improvements can explain much of the dramatic decline in child labor that occurred in Vietnam during the 1990s. While child labor declines in households throughout the per capita expenditure distribution, improvements in economic status appear to explain the declines in child labor in poorer households more so than in rich households. For households that emerge from poverty between 1993 and 1998, per capita expenditure improvements can explain 80 percent of the observed decline in child labor. 
This paper has three main findings in considering subgroups of the population of Vietnam. First, per capita expenditure improvements are better predictors of declines in child labor for boys than for girls. This gender difference may reflect differences in comparative advantage in work for boys relative to girls or it may reflect parental perceptions. In the Vietnamese context, it is often suggested that parents perceive a greater return to investments in boys. Hence, girls are generally more likely to work than boys, and boys are more likely to be working because of poverty within the household. This might explain why changes in expenditure per capita predict the declines in child labor that we observe for boys better than they predict changes for girls. Second, per capita expenditure improvements better predict changes in child labor in large households than in small. The marginal contribution of one child's labor to total household resources may be smaller in larger households. Hence, economic status improvements translate more easily into reductions in child labor in larger households. Third, per capita expenditure improvements best predict declines in child labor for early secondary school age children (12 and 13). Even in 1993, primary school enrollment was nearly universal. Hence, the scope for economic status improvements to affect the economic activities of primary school children is more limited. However, children of secondary school age were much less likely to attend school in 1993 . Thus, there is potentially greater scope for changes in economic status to affect the activities of early secondary school age children. In addition to explaining declines in child labor, per capita expenditure improvements appear to predict a large portion of the increase in school enrollment for children age 12 and 13.

These findings differ from much of the recent evidence on child labor and economic status in four ways. First, the nonparametric tools used in this study allow for (and find) important non-linearities in the correlation between economic status and child labor. Failing to 
account for these non-linearities may lead to misleading results and conclusions. For example, in Vietnam in 1993, I do not find that child labor is sensitive to economic status in the very poorest and very richest households. If most households fell into one of those two regions of per capita expenditure (in reality, they do not), then with parametric methods, I might conclude that there is no link between economic status and child labor as does much of the recent empirical literature on child labor and economic status.

Second, the relationship between economic status and child labor that explains the decline in child labor through time is based on a single point in time. Hence, new technologies, relative price shifts (including the market return to education), and policy, all factors likely to be correlated with economic growth, by construction cannot be the source of the ability of improvements in economic status to explain child labor. Thus, the results of this study provide a rare piece of evidence linking the process of becoming richer to declines in child labor that is not driven by the confounding factors that have drawn so much attention in the recent literature.

Third, the explanatory power of this paper comes from observing the same set of households through time, rather than through comparing fundamentally different households. Thus, the results of this study are based on within household declines in child labor explained by within household changes in economic status. As a result, the findings of large reductions in child labor associated with improvements in economic status reject theories that posit child labor to be driven by preferences or norms that are invariant to the household's economic environment.

Fourth, I am not aware of any other study that examines how child labor responds to a shift in the economic status distribution. This is of considerable policy interest. The process of economic growth and international market integration may include shifts in the economic status distribution of a county, and the empirical evidence on how households respond to this appears 
to be virtually non-existent outside of the present study. If improvements in economic status do not reduce child labor, then to the extent that child labor damages long-term human capital accumulation, improvements in economic status may be transitory and unlikely to lead to longterm or multi-generational improvements in household well-being. Long-term development policy is then better focused on an activist social policy targeted to providing households with incentives to keep children in school and out of work. On the other hand, if improvements in economic status translate into decreases in child labor, then a more activist social policy may be unnecessary. Resources may be better targeted to ameliorating the worst forms of child labor and encouraging more immediate income generation. Further, punitive policies such as trade sanctions designed to punish counties with high levels of child labor may actually increase child labor if trade sanctions lower economic status.

I have ignored econometric issues associated with the effect of child labor on per capita expenditure and with the joint determination of expenditure and the allocation of child time. To interpret (4) as anything more than a conditional expectation, I would need a set of instruments that impact expenditure per capita but not independently child time. This seems difficult in the present case, because as is explicit in section 3.2, anything that affects expenditure also affects child labor supply. The consequence of the joint nature of per capita expenditure and child labor for my analysis is that I cannot in general identify the mechanism through which the 1993 crosssectional relationship between per capita expenditure and child labor predicts child labor in 1998.

A natural question arises about how these results generalize. First, non-linearity in the relationship between child labor and economic status appear very important. Much of the growth in Vietnam between 1993 and 1998 appears to push household economic status across an area of dramatic declines in child labor. I would hesitate to extrapolate from the results found 
here to economic status levels outside of the data. Second, the growth in rural areas that took place during the period of the panel appears to stem from agricultural liberalization and growth in the productivity of the agriculture sector. Improvements in economic status from growth in agriculture may have very different consequences for children than other types of growth. For example, since 1999, Vietnam may have experienced a massive surge in small and medium sized enterprises. This may result in additional, new earning opportunities for children. Whether children take these earnings opportunities depends on the payoff the household perceives to having the child work in these new enterprises. The household must weigh the disutility of having the child work versus the additional income the child's work may bring. The contribution of this paper is not to predict that the desire for less child work will dominate all additional earnings opportunities. Rather, this paper shows that it is not inevitable that the need for additional income will dominate even among the very poor households considered in this paper. In fact, in the present case, improvements in economic status, even in the face of rising earnings opportunities for child laborers, are associated with a very dramatic decline in child labor.

\section{Works Cited}

Acemoglu, D. and J. Angrist (1999): "How Large are the Social Returns to Education? Evidence from Compulsory Schooling Laws.” NBER Working Paper \#7444, December.

Anand, S. and M. Ravallion (1993): "Human Development in Poor Countries: On the Role of Private Incomes and Public Services," Journal of Economic Perspectives, 7(1), 133-150.

Andrews, D. (1991): "Asymptotic Normality of Series Estimators for Nonparametric and Semiparametric Regression Models." Econometrica, 59(2), 307-345.

Baland, J. M. and J. Robinson (2000): "Is Child Labor Inefficient," Journal of Political Economy, August, 108(4), 663-79.

Basu, K. (1999): "Child Labor: Cause, Consequence, and Cure, with Remarks on International Labor Standards," Journal of Economic Literature, 37, 1083-1119.

Basu, K. and P. H. Van (1998): "The Economics of Child Labor," American Economic Review, 88(3), 412-427. 
Basu, K. and Z. Tzannatos (2004): "The Global Child Labor Problem: What do we know and what can we do?" World Bank Economic Review, forthcoming.

Beegle, K., R. Dehejia, and R. Gatti (2003a): "Child Labor Supply and Crop Shocks: Does Access to Credit Matter," World Bank Working Paper 3075, May.

Beegle, K., R. Dehejia, and R. Gatti (2003b): "Why should we care about child labor?" manuscript: Columbia University.

Ben-Porath, Y. (1967): "The Production of Human Capital and the Life Cycle of Earnings," Journal of Political Economy, 75(4), 352-65.

Bholtra, S. and C. Heady (2000): "Child Farm Labour: Theory and Evidence," STICERD Development Economics Working Paper \#24.

Bommier, A. and P. Dubois (2003): "Rotten Parents and Child Labor," Journal of Political Economy, forthcoming.

Boozer, M. and T. Suri (2001): "Child Labor and Schooling Decisions in Ghana," manuscript: Yale University.

Brown, M., and P. Peter (1992): "The Decline of Child Labor in the U.S. Fruit and Vegetable Canning Industry: Law or Economics?” Business History Review, 66, Winter, 723-770.

Brown, D. Deardorff, A., Stern, R. (2003): "Child Labor: Theory, Evidence and Policy", in Basu, K., Horn, H., Roman, L., and Shapiro, J. (eds.), International Labor Standards: History, Theories and Policy, Blackwell, forthcoming.

Deaton, A. (1997): Analysis of Household Surveys. Johns Hopkins University Press: Washington DC.

Deaton, A. and C. Paxson (1998): "Economies of Scale, Household Size, and the Demand for Food," Journal of Political Economy, October, 106(5), 897-930.

Deb, P. and Rosati, F. (2002): "Determinants of Child Labor and School Attendance: The Role of Household Unobservables. Understanding Children's Work Working Paper.

Edmonds, E., Turk, C. (2004): "Child Labor in Transition." in P. Glewwe, N. Agrawal and D. Dollar (eds), Economic Growth, Poverty and Household Welfare: Policy Lessons from Viet Nam. Washington DC: World Bank

Emerson, P. and Souza, A. (2003): "Is There a Child Labor Trap? Intergenerational Persistence of Child Labor in Brazil", Economic Development and Cultural Change, 51 (2), 375-98.

Ennew, J. (1982): "Family Structure, Unemployment, and Child Labour in Jamaica," Development and Change, 13, 1982, 551-63.

Fan, J. and I. Gijbels (1995): Local Polynomial Modelling and Its Applications. Chapman \& Hall: New York.

Fasa, C. (2003): Health Benefits of Eliminating Child Labor. Geneva: International Labour Office Publication.

Foster, A. and Rosenzweig, M. (1996): "Technical Change and Human Capital Returns and Investments: Evidence from the Green Revolution," American Economic Review, 86, 4, September, 931-953. 
General Statistical Office (1994): Viet Nam Living Standards Survey 1992-93. Ha Noi, Viet Nam.

General Statistical Office (1999): Viet Nam Living Standards Survey 1997-98. Ha Noi, Viet Nam.

Glewwe, P. and H. Jacoby (forthcoming): "Economic Growth and the Demand for Education: Is there a Wealth Effect?" Journal of Development Economics.

Glewwe, P. and P. Nguyen (2004): "Economic Mobility in Viet Nam in the 1990s," in P. Glewwe, N. Agrawal and D. Dollar (eds.), Economic Growth, Poverty and Household Welfare: Policy Lessons from Vietnam. Washington DC: World Bank.

Guarcello, L., F. Mealli, and F. Rosati (2003): "Household Vulnerability and Child Labor: The Effect of Shocks, Credit Rationing, and Insurance," Understanding Children's Work Working Paper, July.

Hazan, M. and Berdugo, B. (2002): "Child Labor, Fertility, and Economic Growth," Economic Journal, 112, 810-828.

Heady, C. (2003): "The Effect of Child Labor on Learning Achievement," World Development, $31,385-398$.

Jacoby, H. G. (1994): "Borrowing Constraints and Progress through School: Evidence from Peru," Review of Economics and Statistics, 151-160.

Krueger, A. (1997): "International Labor Standards and Trade," in M. Bruno and B. Pleskovic (eds.) Annual World Bank Conference on Development Economics, 1996 (Washington, D.C.: The World Bank), pp. 281-302.

Levy, V. (1983): "Cropping Pattern, Mechanization, Child Labor, and Fertility in a Farming Economy: Rural Egypt," Economic Development and Cultural Change, July, 33(4), 77791.

Moehling, C. (1999): "State Child Labor Laws and the Decline of Child Labor," Explorations in Economic History, 36, 72-106.

Parsons, D. and Goldin C. (1999): "Parental Altruism and Self-Interest: Child Labor Among Late Nineteenth Century American Families," Economic Inquiry, 27, 1989, 637-59.

Paxson, C. (1993): "Consumption and Income Seasonality in Thailand," Journal of Political Economy, 101(1), February, 39-72.

Psacharopoulos, G. (1997): "Child Labor Versus Educational Attainment: Some Evidence from Latin America," Journal of Population Economics, 10, 1997, 377-86.

Ranjin, P. (2001): "Credit Constraints and the Phenomenon of Child Labor," Journal of Development Economics, 64, 81-102.

Ray, R. (2000): "Analysis of Child Labour in Peru and Pakistan: A Comparative Study," Journal of Population Economics, 13, 2000, 3-19.

Rogers, C. and K. Swinnerton (2001): "Inequality, Productivity, and Child Labor: Theory and Evidence," manuscript: Georgetown University. 
Rogers, C. and K. Swinnerton (2003): "Does Child Labor Decrease when Parental Incomes Rise," manuscript: Georgetown University

Rosenzweig M. and R. Evenson (1977): "Fertility, schooling, and the economic contribution of children in rural India: An econometric analysis," Econometrica 45, 1065-1079.

Schultz, T. W. (1960): "Capital Formation by Education," Journal of Political Economy, December, 571-583.

Swinnerton, K. and C. Rogers (1999): "The Economics of Child Labor: Comment," American Economic Review, 89 (5), 1382-1385.

World Bank (2000): "Vietnam Living Standards Survey, 1997-98: Basic Information." Manuscript, Poverty and Human Resources Division.

World Bank and others (1999): Vietnam Development Report 2000: Attacking Poverty. Joint Report of the Government-Donor-NGO Working Group, Hanoi.

Yang, D. (2003): "Remittances and Human Capital Investments: Child Schooling and Child Labor in the Origin Households of Oversees Filipino Workers," Manuscript: University of Michigan.

\section{Appendix 1: A Semi-Parametric Approach to the Decomposition Model: Controlling for}

\section{Age, Gender, and Household Size Simultaneously}

Household characteristics vary across the distribution of per capita expenditure, and as is evident in section 4 , there is a correlation between household characteristics and the ability of expenditure improvements to explain declines in child labor. In this appendix, within a semiparametric framework, I control for differences in age, gender, and household size simultaneously in an attempt to improve the predictive power of economic status improvements. In order to do this, I have to add greater structure to the empirical model. I estimate:

$$
y_{i t}=\pi_{t}\left(X_{i 93}\right)+\beta_{1 t} H_{i t}+\beta_{2 t} A_{i t}+\beta_{3 t} G_{i t}+u_{i t}
$$

separately for each time period t. $H$ is a vector of household size dummy variables, $A$ is a vector of age dummies, and $G$ is an indicator for gender. I continue to avoid the imposition of any functional form assumptions on the relationship between per capita expenditure and child labor. I do this by following Andrews (1991), modeling the relationship between per capita expenditure 
and child labor with a flexible Fourier form in per capita expenditure, denoted $\pi_{t}\left(X_{i t}\right)$. I

transform per capita expenditure to be on the interval 0 to $2 \pi$ and include the transformed per capita expenditure, its square, $\sin (j x)$, and $\cos (j x)$ in the regression where $j=1,2, . ., 6$.

After estimating the regression in (9) separately for each time period, I use the regression results to project the probability that a 12 year old boy in a household with 6 members works for each possible household per capita expenditure in 1993:

$$
\bar{y}_{i, 93}=\pi_{93}\left(X_{i, 93}\right)+\beta_{1,93}(H=6)+\beta_{2,93}(A=12)+\beta_{3,93}(G=0) .
$$

Similarly, I use the 1998 results to make the same projection for the 1998 data:

$$
\bar{y}_{i, 98}=\pi_{98}\left(X_{i, 93}\right)+\beta_{1,98}(H=6)+\beta_{2,98}(A=12)+\beta_{3,98}(G=0) .
$$

I could equivalently just plot the relationship between child labor and expenditure per capita given by $\pi_{93}\left(X_{i 93}\right)$ and $\pi_{98}\left(X_{i 98}\right)$ for any other child. The choice of a reference child shifts the intercept but does not influence the relationship between per capita expenditure and child labor, because my functional form assumption does not allow interactions between per capita expenditure, age, gender, and household size. ${ }^{20}$

As with the fully nonparametric work above, I mimic the form of (9) to model how per capita expenditure in 1993 maps to per capita expenditure in 1998:

$$
X_{i, 98}=\theta_{98}\left(X_{i, 93}\right)+\alpha_{1,98}(H=6)+\alpha_{2,98}(A=12)+\alpha_{3,98}(G=0)
$$

\footnotetext{
${ }^{20}$ The evidence in the text highlights important interactions between gender, household size, age, per capita expenditure, and child labor. In asking the question "How does controlling for age, gender, and household size differences, change the explanatory power of living standards improvements," I am ignoring the interaction of all these factors.
} 
By plugging $\theta_{98}\left(X_{i, 93}\right)$ into (10) I can calculate the predicted child labor in 1998 based on the relationship between expenditure per capita and child labor in 1993 after controlling for household size and age differences:

$$
\breve{y}_{i, 98}=\pi_{93}\left(\theta_{98}\left(X_{i, 93}\right)\right)+\beta_{1,93}\left(H_{i, 93}=6\right)+\beta_{2,93}\left(A_{i, 93}=12\right)+\beta_{3,93}\left(G_{i, 93}=0\right) .
$$

Figure 9 presents estimates of $\bar{y}_{i, 93}, \bar{y}_{i, 98}$, and $\breve{y}_{i, 98}$.

Upon controlling for age and household size differences, per capita expenditure improvements explain 71 percent of the reduction in child labor for households that exit poverty. The local regression approach in the text explains 80 percent of the decline in child labor in this group, and linear regression explains 51 percent of the observed decline in this group. As with the linear form above, the series estimator over-smoothes in the neighborhood of the poverty line and therefore misses the large decline in child labor that comes in households that move from above to below the poverty line. However, the series estimator out-performs the linear regression, because it does allow for some of the curvature that seems important. I have also estimated (6) - (9) including community fixed effects for each year. Hence, I identify the relationship between child labor and per capita expenditure from within community variation in economic status. This picture appears identical to figure 9 (aside from a slight shift in the scale) and consequently has not been included here.

\section{Appendix 2: Household Livings Standards in Adult Equivalents}

Controlling for household size, age, and gender differences (as in appendix 1) captures variation in child labor associated with the different tasks required at various household sizes or for differences in the activities of children at various ages and genders. However, if economies of scale are important within the household or if children have different consumption needs (or 
"costs") than adults, these regression controls alone do not eliminate the resulting mismeasurement of economic status. In this appendix, I consider different assumptions about economies of scale within the household and the equivalence of adults and children in order to see if it is possible to further improve the predictive power of improvements in expenditure.

I define an adult equivalent, $E$, as: $E=(A+\alpha K)^{\theta}$. The parameter $\alpha$ controls the costs of children (in this case, individuals age $0-15$ ) relative to adults so that $A+\alpha K$ is effective household size, while the parameter $\theta$ controls the degree of economies of scale with respect to effective household size, converting effective household size into equivalent adults; note the lower is $\theta$, the greater the economies of scale. There is not a consensus within the literature as to what assumptions should be made about $\alpha$ and $\theta$ (Deaton and Paxson 1998). Hence I consider several possible values of each, letting both $\alpha$ and $\theta$ vary between .5 and 1 . The results of calculating (10) - (13) with different assumptions on $\alpha$ and $\theta$ are in figure 10. Each row of figure 10 represents a different assumption about the costs of children. In the first row, I consider a child to be half an adult. In the bottom row, a child is equivalent to an adult. Each column of figure 10 represents a different assumption about economies of scale in the household. In the far left column, a quadrupling of the effective household size (for a given total expenditure) decreases household economic status by one half. In the far right column, a quadrupling of the effective household size generates a measure of economic status that is one fourth of its original level. In each picture, the top line contains the 1993 line (eq. 8), the middle $(+)$ line is the predicted level of child labor based on expenditure improvements (eq. 11), and the bottom (o) line is the actual 1998 level of child labor (eq. 9).

In general, the results of figure 10 do not provide strong evidence that the predictive power of expenditure varies substantively across assumptions made in computing adult 
equivalence. The range pictured in each graph in figure 10 is from the 5 th to 90 th percentiles. For this entire range space, the predictive power of expenditure ranges from a low of 64 percent ( $\alpha=.5$ and $\theta=1$ ) to a high of 71 percent ( $\alpha=1$ and $\theta=.75$ ). Within this small amount of variation, there are two generalizations suggested by figure 10. First, given the economies of scale assumption, the smaller the cost of children, the poorer the predictive power of expenditure improvements. Second, assuming the presence of some economies of scale enhances the predictive power of expenditure improvements given the assumption about costs of children. That is, the predictive power of expenditure improvements is greater when $\theta$ is less than 1 . Overall, however, none of the economies of scale or child cost assumptions considered in this appendix significantly outperform the $\{\alpha=1, \theta=1\}$ assumption used in the body of this paper. 
Table 1: Child Labor by Age and Through Time for Children

Percent of children participating in various types of work

\begin{tabular}{|c|c|c|c|c|c|c|c|c|}
\hline \multirow[b]{3}{*}{ Age } & \multicolumn{4}{|c|}{1993} & \multicolumn{4}{|c|}{1998} \\
\hline & \multicolumn{3}{|c|}{ Outside } & \multirow{2}{*}{$\begin{array}{l}\text { Fam } \\
\text { Bus }\end{array}$} & \multicolumn{3}{|c|}{ Outside } & \multirow{2}{*}{$\begin{array}{l}\text { Fam } \\
\text { Bus }\end{array}$} \\
\hline & Work & House & Agric. & & Work & House & Agr & \\
\hline 6 & 1.5 & 0.0 & 1.3 & 0.2 & 1.1 & 0.0 & 1.1 & 0.0 \\
\hline 7 & 7.3 & 0.2 & 6.8 & 0.3 & 2.2 & 0.0 & 2.2 & 0.0 \\
\hline 8 & 13.1 & 0.1 & 12.2 & 0.9 & 7.9 & 0.0 & 7.9 & 0.2 \\
\hline 9 & 18.9 & 0.2 & 17.5 & 1.1 & 7.9 & 0.2 & 7.0 & 1.1 \\
\hline 10 & 27.1 & 0.3 & 25 & 2.3 & 13.1 & 0.0 & 12.6 & 0.5 \\
\hline 11 & 29.8 & 1.1 & 26.7 & 3.4 & 22.7 & 0.1 & 21.3 & 1.8 \\
\hline 12 & 40.7 & 3.2 & 31.7 & 7.5 & 28.7 & 0.7 & 26.5 & 2.1 \\
\hline 13 & 48.0 & 3.0 & 40.5 & 6.8 & 35.6 & 1.9 & 31.3 & 4.1 \\
\hline 14 & 61.0 & 5.5 & 49.1 & 10.8 & 40.1 & 3.9 & 32.9 & 5.9 \\
\hline 15 & 69.4 & 9.7 & 52.4 & 12.6 & 49.3 & 5.3 & 40.3 & 8.0 \\
\hline
\end{tabular}

All means are weighted to be nationally representative for the indicated year. "Work" refers to participation in the last 7 days in any of the indicated work categories. "Outside House" indicates work outside of the child's household for pay (cash or in-kind). "Agric" indicates work inside the child's own household in agricultural activities. "Fam Bus" refers to work inside the child's own household in a family business or enterprise other than agriculture.

Table 2: Child Labor by Quintile of Per Capita Expenditure in 1993 Percent of children participating in various types of work, Panel Households Only

\begin{tabular}{|c|c|c|c|c|c|c|c|c|}
\hline \multirow[b]{2}{*}{ Quintile } & \multicolumn{4}{|c|}{1993} & \multicolumn{4}{|c|}{1998} \\
\hline & Work & $\begin{array}{l}\text { Outside } \\
\text { House }\end{array}$ & Agr & Fam Bus & Work & $\begin{array}{l}\text { Outside } \\
\text { House }\end{array}$ & Agr & Fam Bus \\
\hline 1 & 38.8 & 3.1 & 34.1 & 3.7 & 32 & 1.4 & 29 & 3.3 \\
\hline 2 & 36.8 & 2.1 & 33.2 & 2.9 & 25.2 & 1.3 & 22.8 & 2.2 \\
\hline 3 & 32.9 & 1.8 & 27.6 & 4.5 & 21.9 & 1.6 & 17.7 & 3 \\
\hline 4 & 26.1 & 1.8 & 20.4 & 5.5 & 12.9 & 0.9 & 11.4 & 2 \\
\hline 5 & 15.6 & 1.1 & 10.2 & 5.4 & 4.8 & 0.6 & 2.8 & 2 \\
\hline
\end{tabular}

Quintiles are household quintiles of 1993 per capita expenditure. See table 2 for column definitions.

Table 3: Percent of Decline in Child Labor Explained by Improvements in Per Capita Expenditures: Comparison of Linear and Local Decompositions

\begin{tabular}{lll}
\hline \hline & Linear & Local \\
\hline Poorest 25 percent & 83 & 58 \\
Poorest 50 percent & 66 & 71 \\
Poorest 75 percent & 58 & 64 \\
Households Exit Poverty & 51 & 80 \\
Population & 52 & 59 \\
\hline \hline
\end{tabular}

Each cell contains the fraction of the actual decline in child labor that can be explained by improvements in per capita expenditures using the methodology described in the text The percent of the decline explained for the range indicated by the row label is computed by taking a weighted average over the specified range, where the weights assigned to any point in the range are kernel density estimates of the mass in the neighborhood of the point in 1993 (as in the 1993 distribution in figure 1). 
Table 4: Percent of Decline in Child Labor Explained by Living Standards Improvements, Various Population Groups

\begin{tabular}{|c|c|c|c|c|c|}
\hline & \multicolumn{5}{|c|}{$\begin{aligned} \text { Households } \\
\end{aligned}$} \\
\hline & \multirow{2}{*}{$\begin{array}{r}\text { Poorest } 25 \\
\text { percent }\end{array}$} & Poorest 50 & \multirow{2}{*}{$\begin{array}{r}\text { Poorest } 75 \\
\text { Percent }\end{array}$} & \multicolumn{2}{|l|}{ Exiting } \\
\hline & & Percent & & Poverty & Population \\
\hline & (1) & (2) & (3) & (4) & (5) \\
\hline Full Sample & 58 & 71 & 64 & 80 & 59 \\
\hline \multicolumn{6}{|l|}{ Gender } \\
\hline Boys & 80 & 88 & 75 & 86 & 69 \\
\hline Girls & 49 & 62 & 58 & 78 & 54 \\
\hline \multicolumn{6}{|l|}{ Age Group } \\
\hline 6-11 & 60 & 77 & 70 & 85 & 64 \\
\hline $12-13$ & 83 & 99 & 90 & 125 & 78 \\
\hline 12-13, Schooling & 58 & 58 & 34 & 56 & 34 \\
\hline $14-15$ & 70 & 69 & 65 & 67 & 61 \\
\hline \multicolumn{6}{|l|}{ Household Size } \\
\hline$<=4$ & 22 & 6 & 14 & 8 & 25 \\
\hline$>=5 \&<=6$ & 33 & 60 & 58 & 72 & 52 \\
\hline$>=7$ & 85 & 76 & 70 & 95 & 62 \\
\hline
\end{tabular}

Each cell contains the fraction of the actual decline in child labor that can be explained by improvements in expenditures using the methodology described in the text and the weighting scheme described in the note to table 3. Each row specifies a different population subgroup. Each column indicates the region of the 1993 PCX distribution for which the fraction explained is calculated. Column 4 refers to the part of the population that was below the 1993 poverty line in 1993 but whose 1998 expenditure per capita is above the 1993 poverty line.

Table 5: Percent of Decline in Child Labor Explained by Living Standards Improvements: Comparison of Various Decompositions

\begin{tabular}{llll}
\hline \hline & Linear-OLS & Series & Local \\
\hline Poorest 25 percent & 83 & 69 & 58 \\
Poorest 50 percent & 66 & 73 & 71 \\
Poorest 75 percent & 58 & 68 & 64 \\
Households Exit Poverty & 51 & 74 & 80 \\
Population & 52 & 60 & 59 \\
\hline \hline
\end{tabular}

Each cell contains the fraction of the actual decline in child labor that can be explained by improvements in expenditures. The percent of the decline explained for the range indicated by the row label is computed by taking a weighted average over the specified range, where the weights assigned to any point in the range are kernel density estimates of the mass in the neighborhood of the point in 1993 (as in the 1993 distribution in figure 1). Column 1 results are based on the linear regression of a child labor indicator on per capita expenditure in 1993 (section 4.2 ). Column 2 contains the results from a series expansion in per capita expenditure (appendix 1). Column 3 contains the basic nonparametric decomposition results from the text (section 3.3). 


\section{Figure 1: Per Capita Expenditure Distribution in 1993 and 1998}

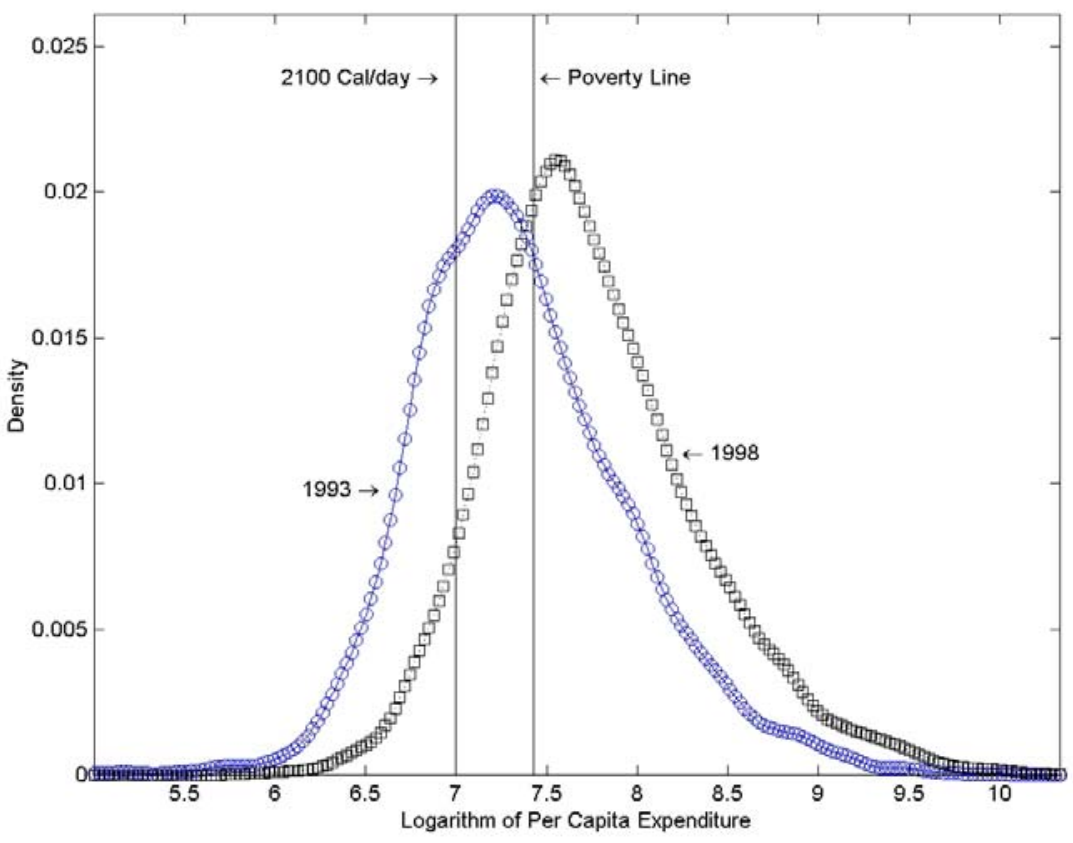

Kernel density estimates of the distribution of the logarithm of per capita expenditure. Densities are computed with a Gaussian kernel and a bandwidth of 0.095 in 1993 and 0.087 in 1998. Each density is weighted to be nationally representative of the Vietnamese population for the indicated year.

Figure 2: Local Regression of the Probability of Participating in Market Work on the Logarithm of Per Capita Expenditure, 1993

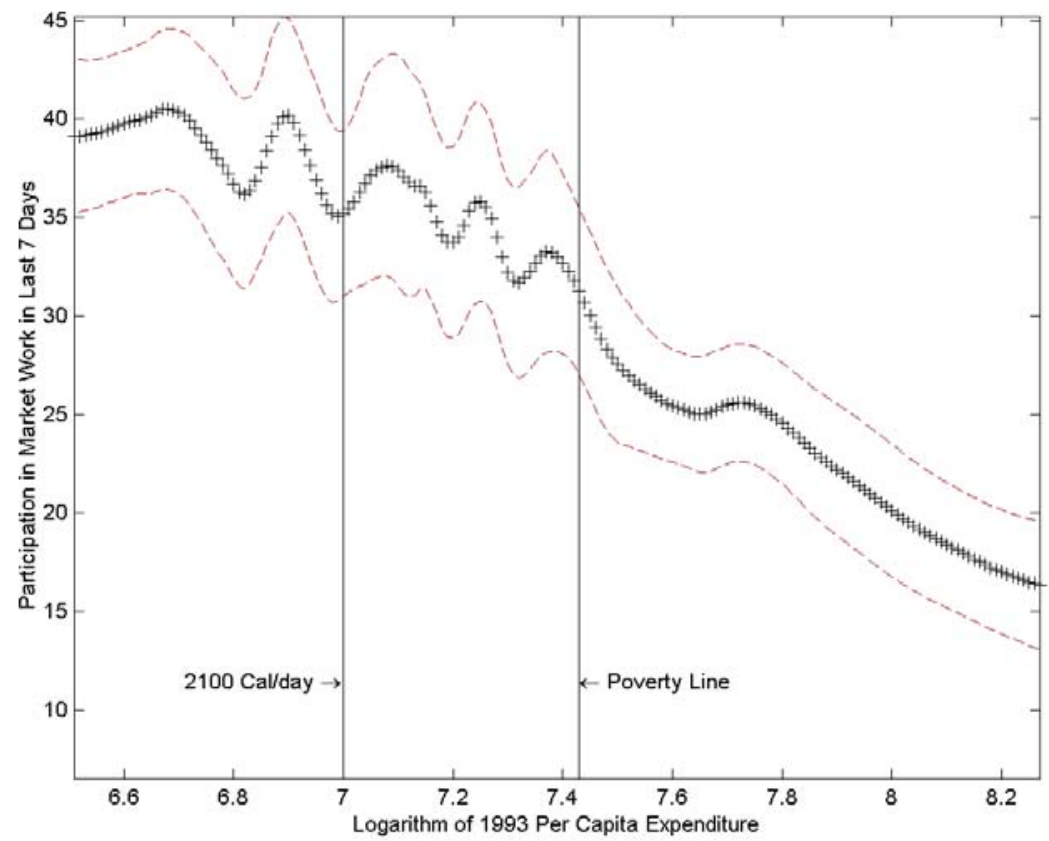


Figure 3: Local Regression of the Logarithm of Per Capita Expenditure in 1998 on the Logarithm of Per Capita Expenditure in 1993

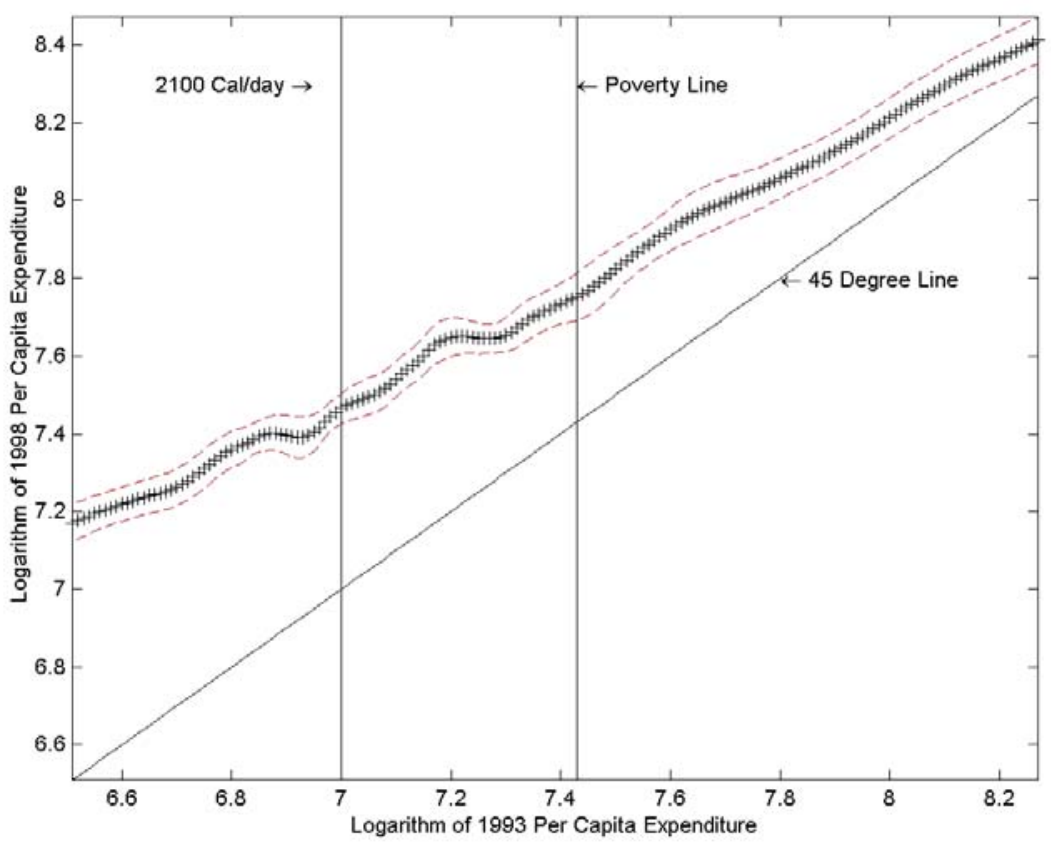

Figure 4: Explaining Changes in Child Labor with Changes in Per Capita Expenditure, Local Regression Results

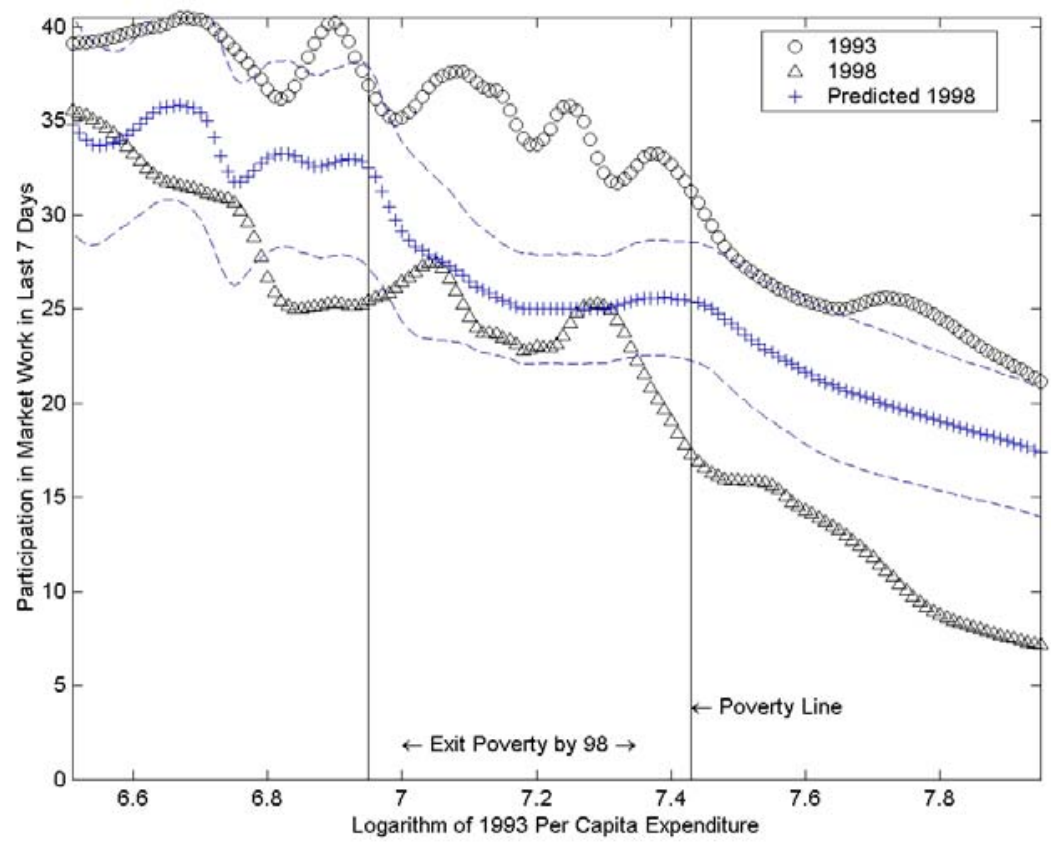


Figure 5: Comparison of Declines in Child Labor between Households that Increase and Decrease Per Capita Expenditures, Limited to Households in the Region of 1993 Distribution that Exits Poverty between 1993 and 1998

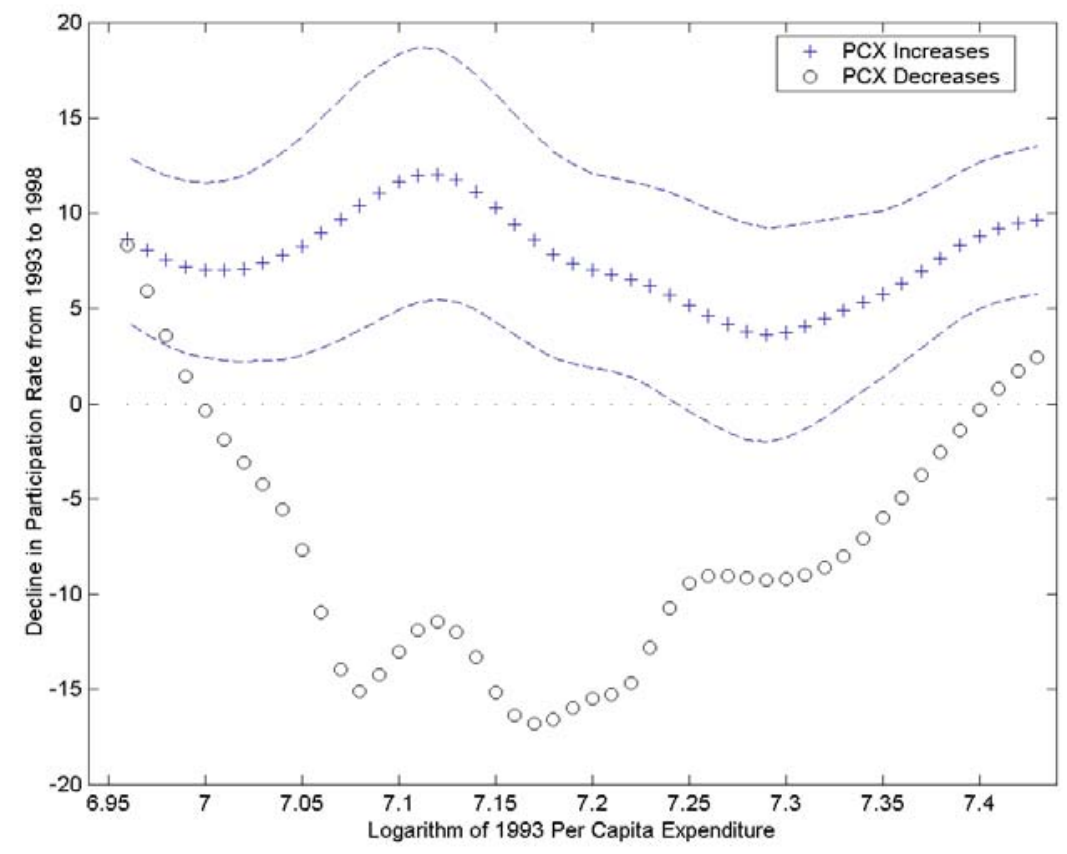

Figure 6A: Explaining Changes in Child Labor with Changes in Per Capita Expenditure, Local Regression Results for Girls

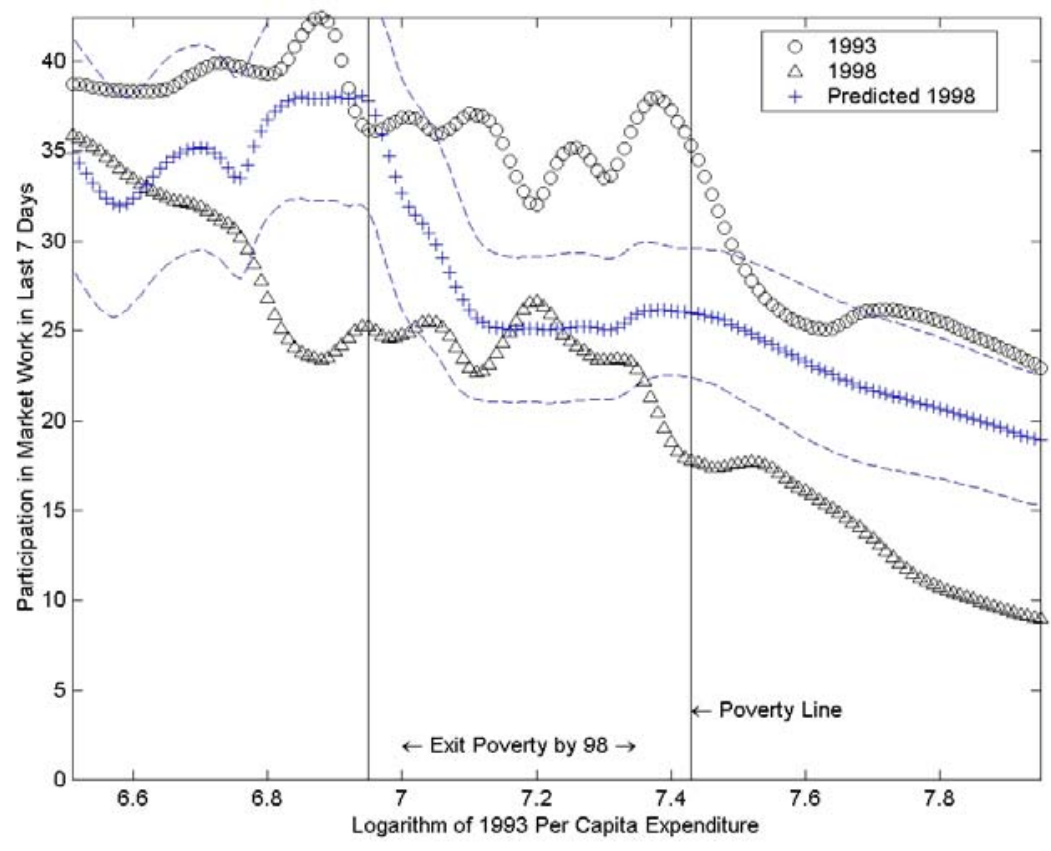


Figure 6B: Explaining Changes in Child Labor with Changes in Per Capita Expenditure, Local Regression Results for Boys

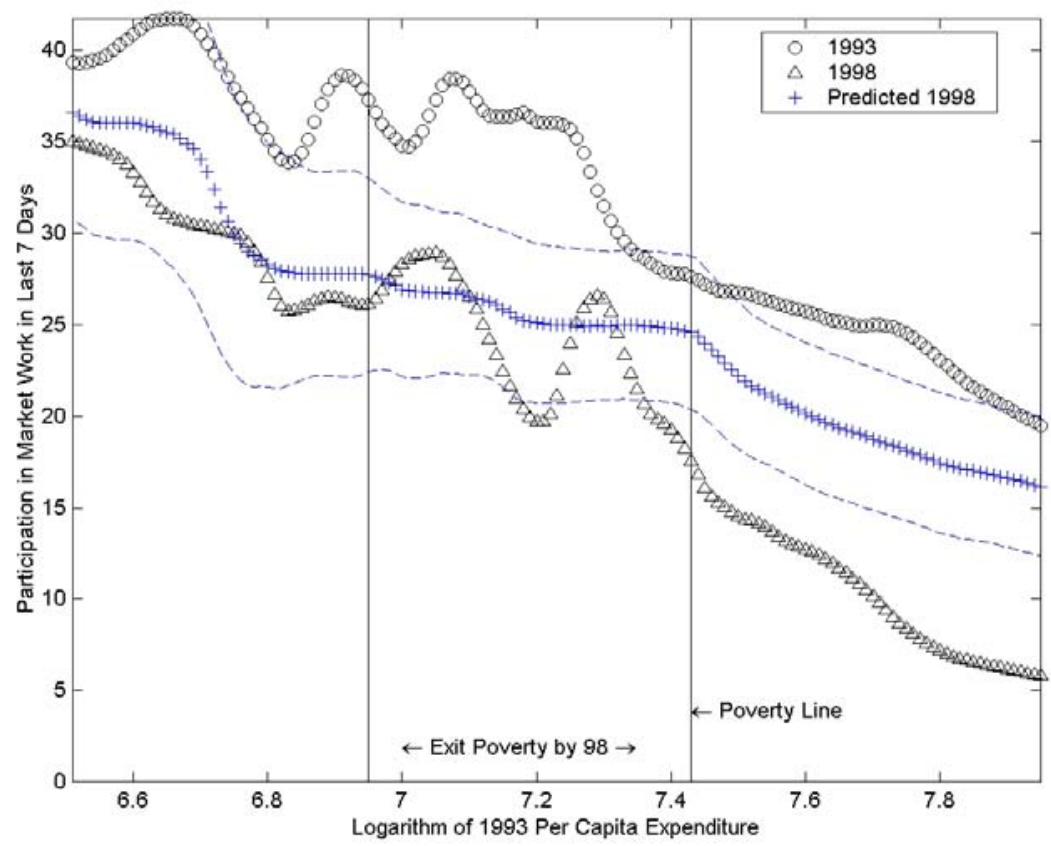

Figure 7A: Explaining Changes in Child Labor with Changes in Per Capita Expenditure, Local Regression Results for Children Between the Ages of 6 and 11

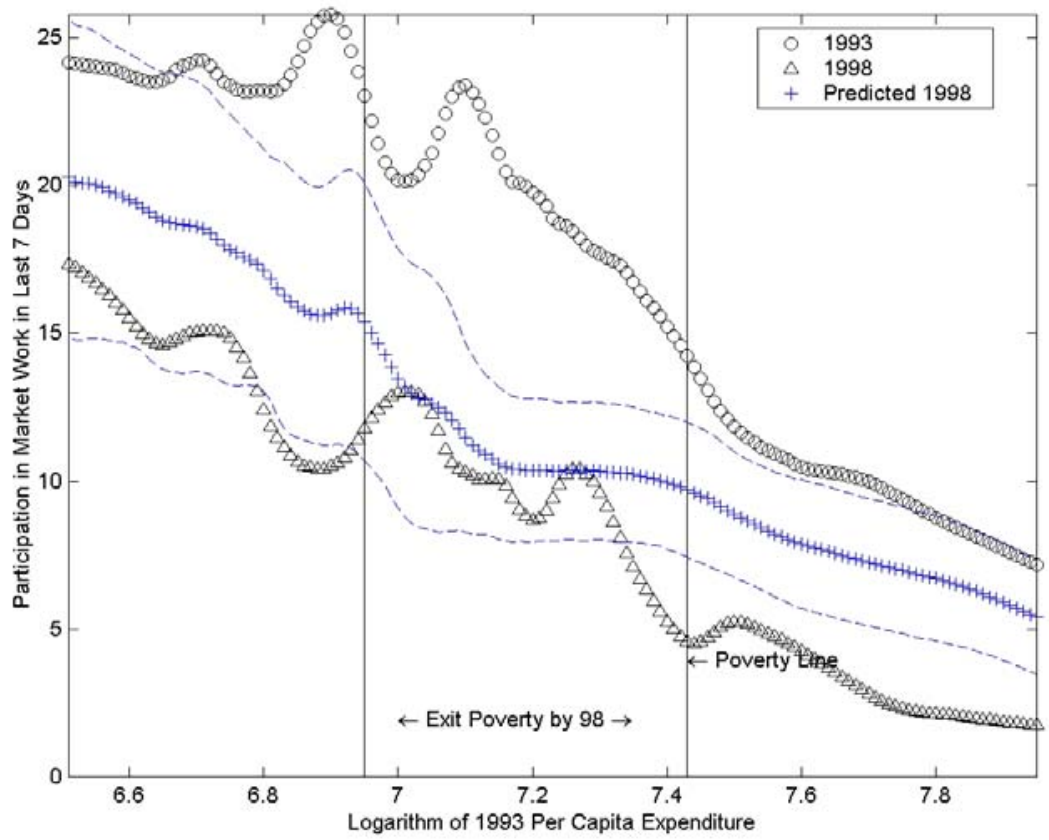


Figure 7B: Explaining Changes in Child Labor with Changes in Per Capita Expenditure, Local Regression Results for Children, Ages 12 and 13

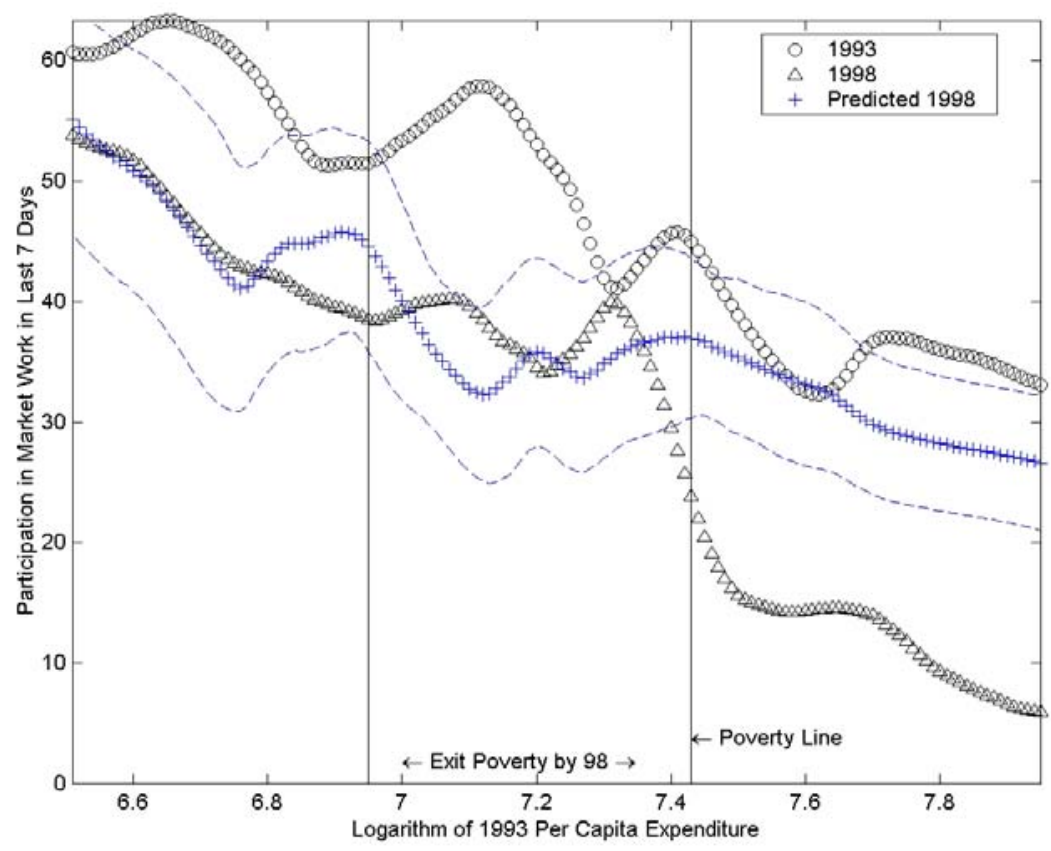

Figure 7C: Explaining Increases in School Attendance with Changes in Per Capita Expenditure, Local Regression Results for Children, Ages 12 and 13

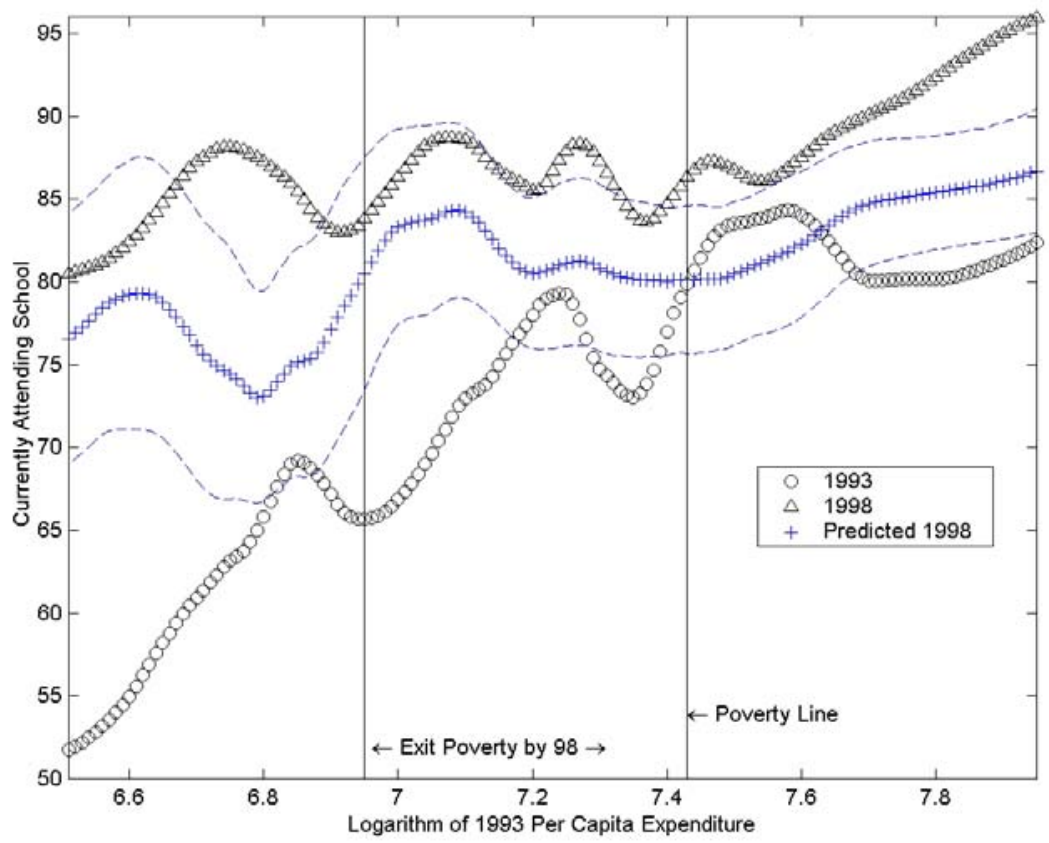


Figure 7D: Explaining Changes in Child Labor with Changes in Per Capita Expenditure, Local Regression Results for Children Ages of 14 and 15

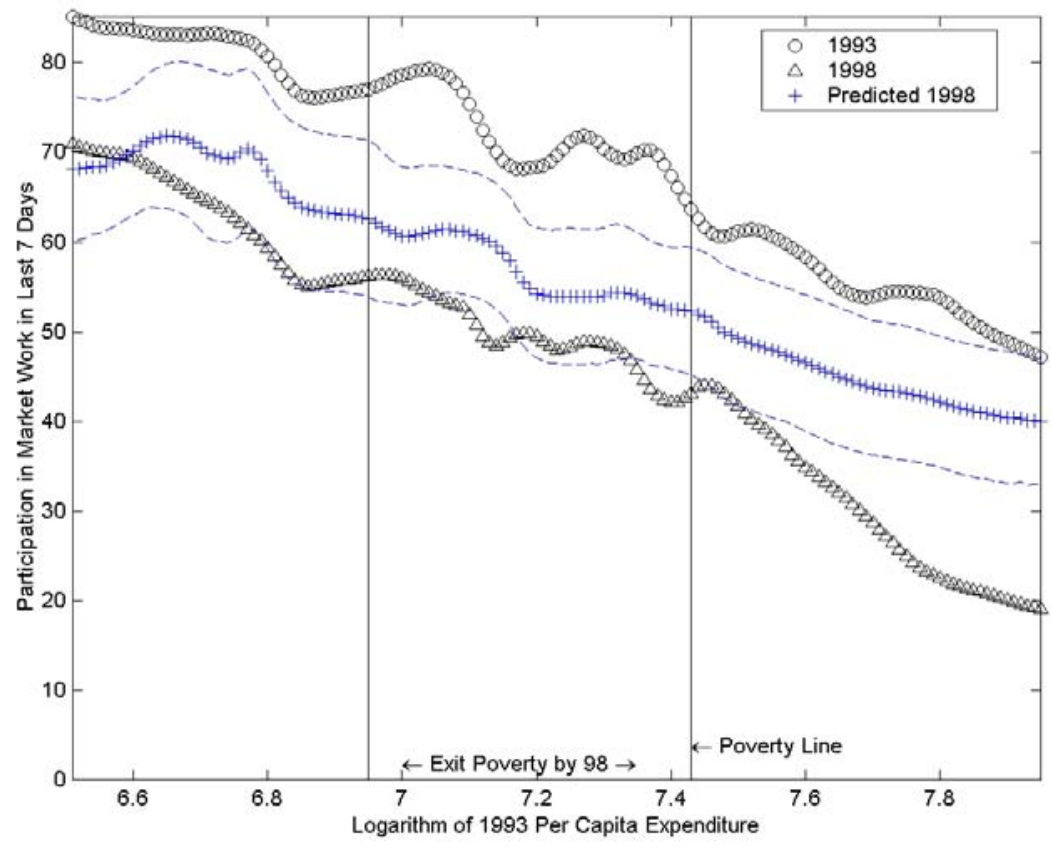

Figure 8A: Explaining Changes in Child Labor with Changes in Per Capita Expenditure, 4 or fewer members

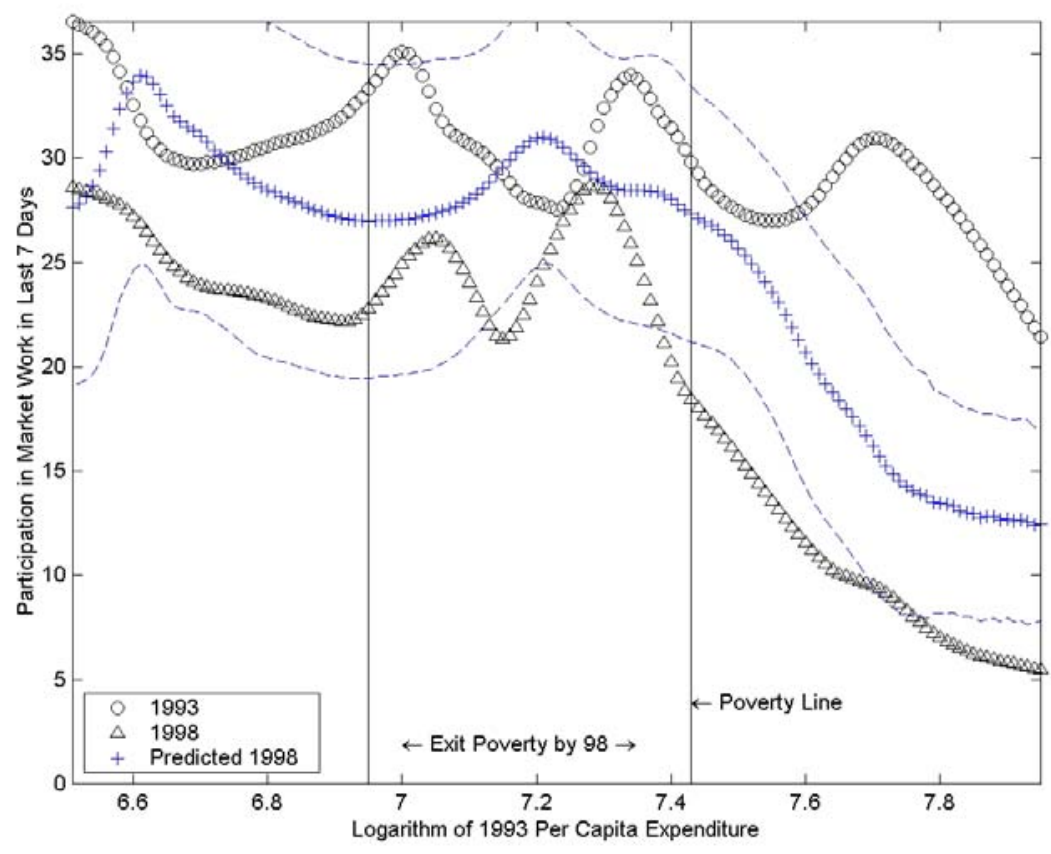


Figure 8B: Explaining Changes in Child Labor with Changes in Per Capita Expenditure, 5 or 6 members

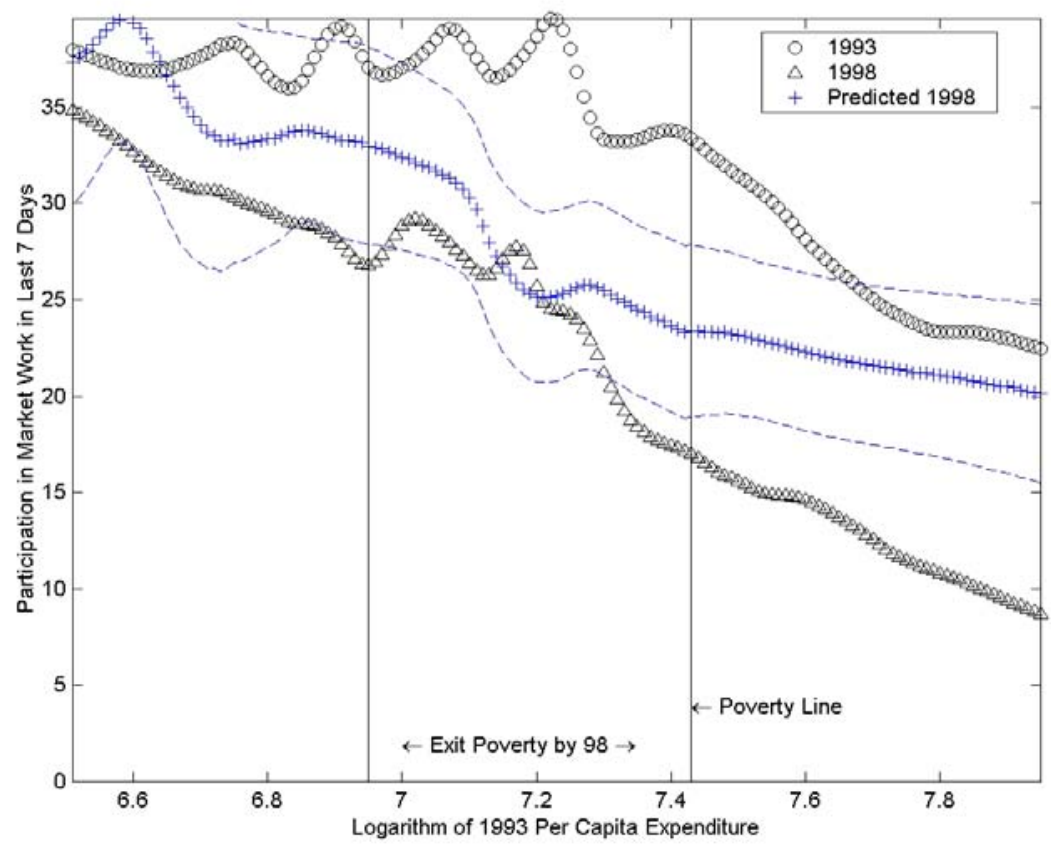

Figure 8C: Explaining Changes in Child Labor with Changes in Per Capita Expenditure, Local Regression Results for Children in Households with 7 or more members

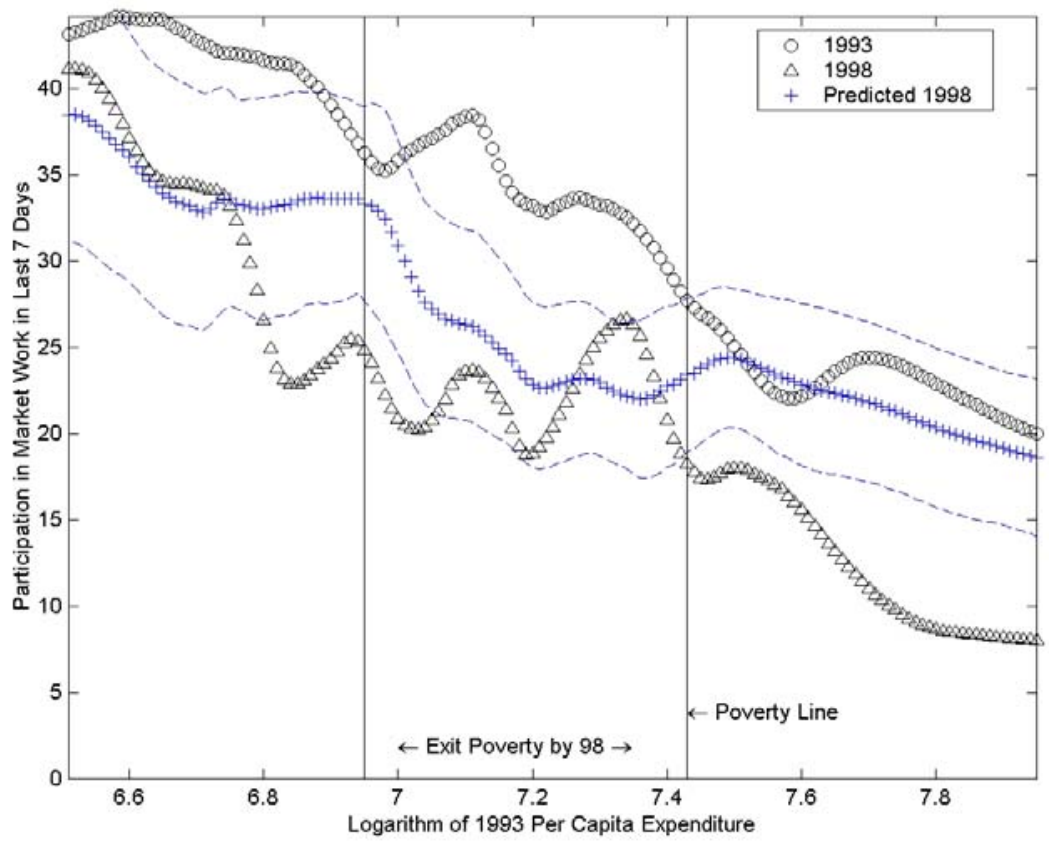


Figure 9: Explaining Changes in Child Labor with Changes in Per Capita Expenditure, Semi-Parametric Regression Results

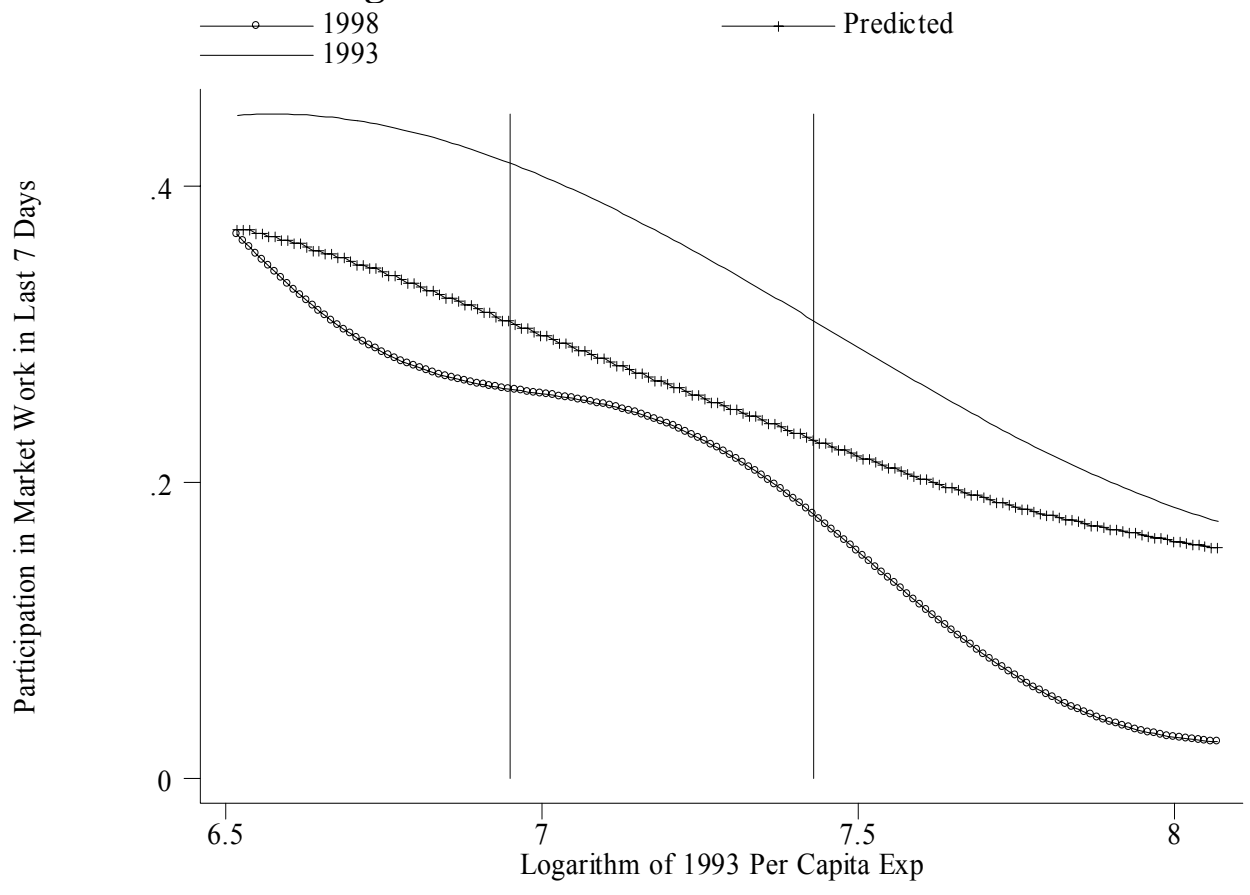


Figure 10: Adult Equivalence Assumptions and the Predictive Power of Economic Status Improvements

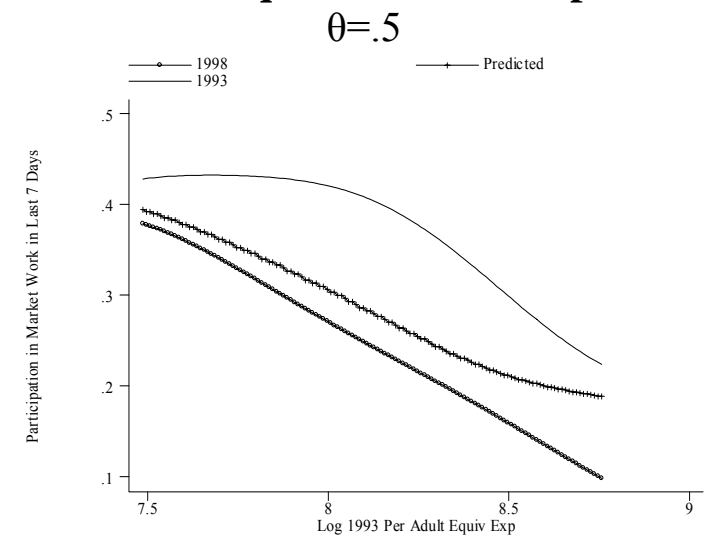

.75

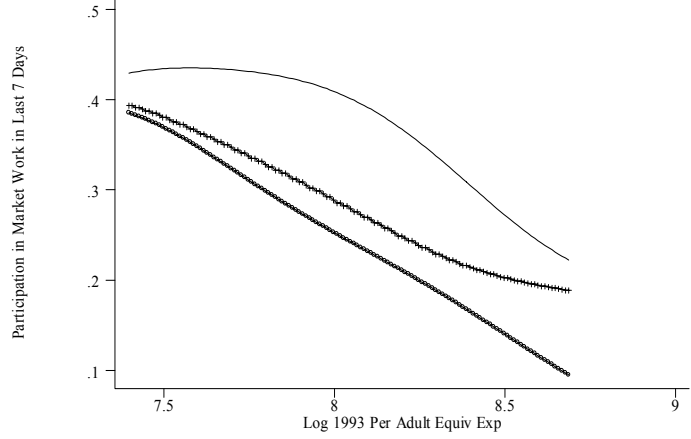

1

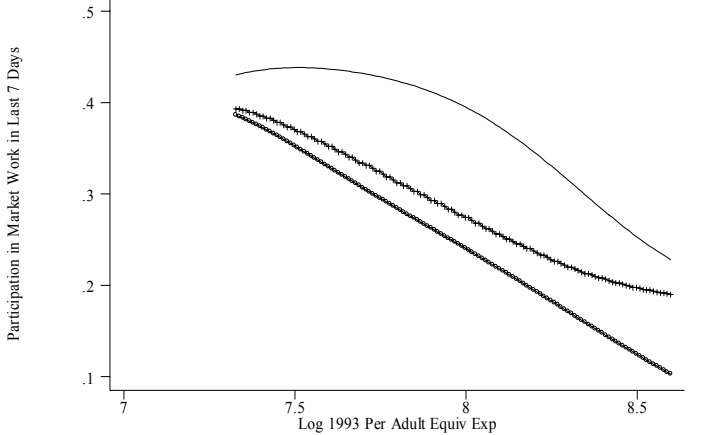

$\theta=.75$
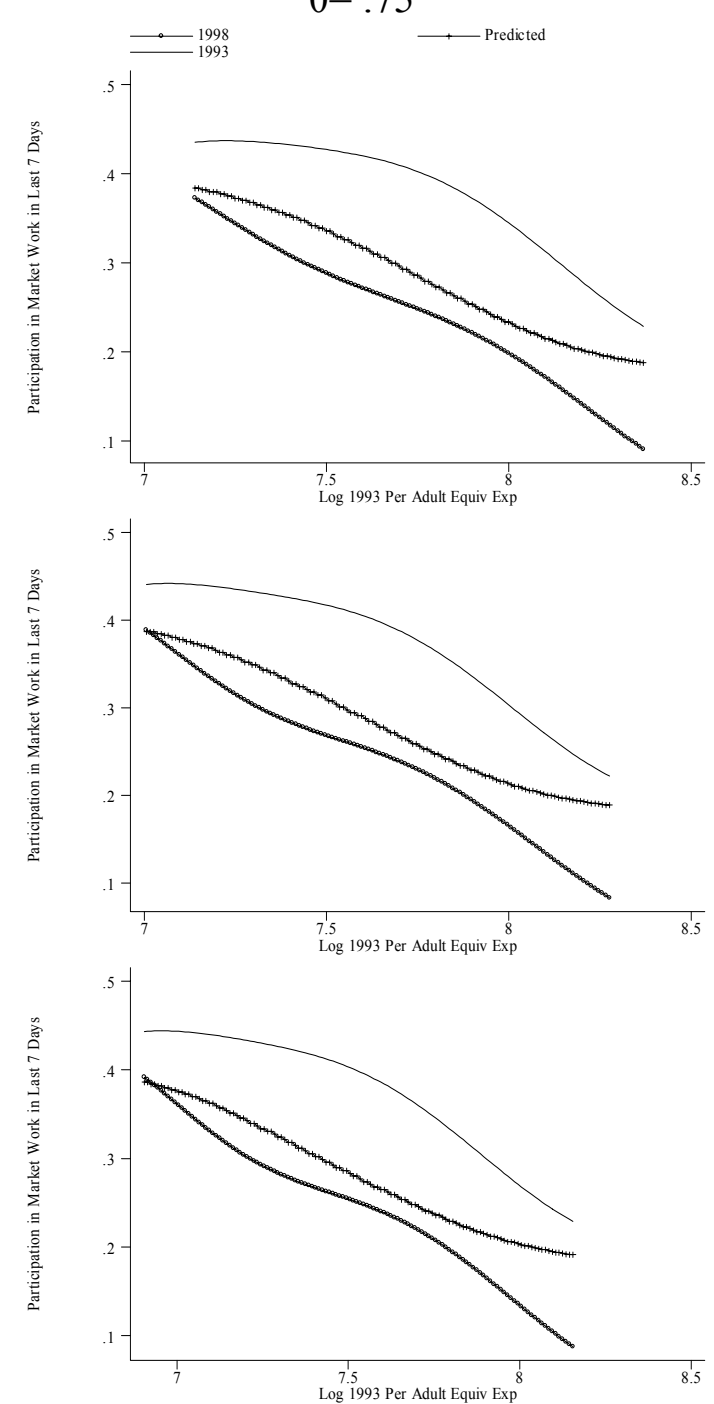

$\theta=1$
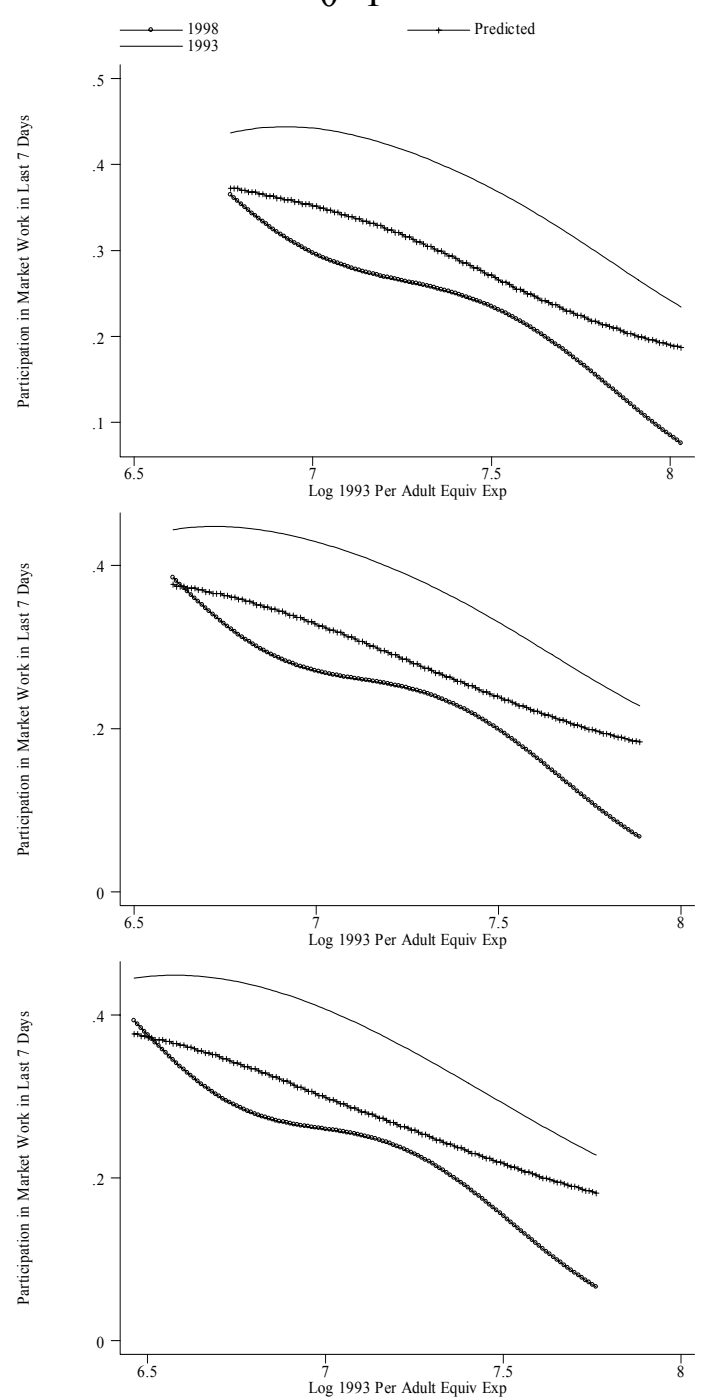

An adult equivalent is defined as $E=(A+\alpha K)^{\theta}$. A is the number of adults (age $\left.>15\right)$ and $\mathrm{K}$ is the number of kids $(0-15)$. All graphs are pictured from the $5^{\text {th }}$ to $90^{\text {th }}$ percentiles. Dependent variable is an indicator that a child participates in market work in the last 7 days. 